\title{
Midwives and their Role in the Reduction of Direct Obstetric Deaths during the late Nineteenth Century: The Sundsvall Region of Sweden (1860-1890)
}

\author{
STEPHAN CURTIS*
}

Maternal mortality remains a cause of legitimate concern in developing parts of the world where rates often exceed 650 per 100,000 live births - at least twenty times higher than in the developed world, and appears impervious to all efforts to reduce it. ${ }^{1}$ Overwhelming poverty, insufficient health care, and the paucity of well-developed and thoroughly integrated programmes to reduce maternal mortality help ensure that these rates are comparable to, if not actually higher than, those found in some of the most unhealthy European cities and regions of the nineteenth century.

Contemporary studies of maternal mortality in the developing world often ignore the power of traditional cultures and their influence on birth practices. This lack of attention is surprising because of the very real impact that such learned behaviour can have on the willingness to accept new and alien methods. Many researchers instead choose to perceive the problem of high mortality among pregnant women and new mothers as one that a more efficient delivery of modern medical techniques should easily solve. In the rare instances when the role of culture enters the discussion it is perceived as a minor obstacle that diligent medical practitioners and committed politicians could easily overcome if only they had the initiative to do so. In the same way it is frequently alleged that the simple solution to high maternal mortality requires only an infusion of money to pay the salaries of more doctors and midwives who can introduce the latest techniques and medicines to an increasingly "enlightened" population.

The recent work of Gijs Walraven and Andrew Weeks responds to these arguments and emphasizes the need for medical practitioners to overcome cultural and social distances in developing nations of today. In their judgment:

Those assisting births and providing maternal care need to have the trust and respect of the community. Midwives from outside the area would have to adapt to local customs.... Cultural

(C) Stephan Curtis 2005

* Stephan Curtis, PhD, Department of History, Memorial University of Newfoundland, St. John's, NL A1C 5S7, Canada.

I am very grateful to Associated Medical Services and the Wellcome Trust for their generous financial support, and to Drs Irvine Loudon and Ulf Högberg for their valuable assistance. Thanks also to my colleagues at the Demographic Data Base in Umeå, Sweden, for their comments when I presented an earlier version of this paper, and to Siv Styrbjörn at ArkivData in
Norrköping for responding to my numerous and often frantic requests for information. Finally, I wish to thank the referees and editors of this journal for their insightful suggestions for improving this work.

${ }^{1}$ D Rush, 'Nutrition and maternal mortality in the developing world', Am.J. Clin. Nutr., 2000, 72 (suppl): 212-40s, p. 214s. During the past twenty years, attempts to reduce maternal mortality have not been overly effective. Carla AbouZahr and Tessa Wardlaw, 'Maternal mortality at the end of a decade: signs of progress?', Bull. World Health Organ., 2001, 79: 561-73, p. 566. 


\section{Stephan Curtis}

sensitivity and the ability to have one's help sought and advice followed may be just as important as technical skill in making an impact on maternal health. ${ }^{2}$

This study of maternal mortality in the parishes of the Sundsvall region during the nineteenth century reveals just how applicable their assessment is when examining past societies.

Notwithstanding the ability of traditional culture to thwart even the most determined efforts to change it, a recent article illustrates the persistent tendency of accentuating the role that financial capital and political desire plays in the reduction of maternal mortality. Vincent De Brouwere, René Tonglet, and Wim Van Lerberghe assert that political will and well-trained midwives were instrumental to the reduction of maternal mortality in Europe during the nineteenth and twentieth centuries. ${ }^{3}$ The authors further suggest that the developing countries of today need do little more than follow the European model of embracing political acumen and comprehensive medical training to achieve similar results.

A brief summary of the provision of medical care in nineteenth-century Sweden illustrates that even in that country the situation was not as advanced as these authors would have us believe. The Swedish state, it is true, introduced a largely successful programme that dramatically increased the number of trained midwives during the course of the nineteenth century. This initiative gave Swedish women a much higher likelihood of surviving childbirth than their counterparts elsewhere in Europe. That said, to assume that whatever the politicians wanted the midwives to achieve is what actually happened, even in the most isolated parts of the country, is rather naïve. It is impossible to prove the authors' conclusion that maternal mortality declined in Europe because of "political commitment, availability of effective techniques, and assistance to most deliveries provided by trained health professionals able to "culturally' integrate such a technology". 4 Their assertion certainly is not true before the very end of the nineteenth century and perhaps not until the early 1900s.

The major shortcoming of focusing upon the role of politicians and medical practitioners is that the women who were about to give birth, and upon whom new techniques were practised, are entirely ignored. We are instead led to believe that they simply acquiesced in the wishes of the midwives, the doctors who trained and supervised them, and the politicians who financed the provision of medical care. How could traditional culture and practices compete against such a monolith of state authority and medical dominance? As this study will show, it did so quite well in the rural parishes of Sweden at least until the 1890s.

To be fair, there have been some notable studies that have abandoned this top-down model in favour of the parturients themselves and the culture that influenced their decisions about who would attend the birth of their children. ${ }^{5}$ Instead of a world in which women

\footnotetext{
${ }^{2}$ Gijs Walraven and Andrew Weeks, 'The role of (traditional) birth attendants with midwifery skills in the reduction of maternal mortality', Trop. Med. Int. Health, 1999, 4: 527-9, p. 527.

${ }^{3}$ V De Brouwere, R Tonglet, and W Van Lerberghe, 'Strategies for reducing maternal mortality in developing countries: what can we learn from the history of the industrialized West?' Trop. Med. Int. Health, 1998, 3: 771-82.
}

\footnotetext{
${ }^{4}$ Ibid., p. 773. What this cultural integration actually entailed is left to the readers' imagination.

${ }^{5}$ For Norway see, Kristina Kjærheim, Mellom kloke koner og kvitkledde menn: jordmorvesenet pa 1800-talet, Oslo, Norske Samlaget, 1987; and for Sweden, Pia Höjeberg, Jordemor: barnmorskor och barnföderskor i Sverige, Stockholm, Carlssons, 1991.
} 


\section{Midwives and their Role in the Reduction of Direct Obstetric Deaths}

responded passively to the wishes of trained medical practitioners we find a medical labyrinth in which doctors and midwives competed for patients with folk healers, quacks, and help-women. The methods and remedies of the former supplemented those of the latter but seldom, if ever, completely replaced them. It is in this complex medical world of the nineteenth century that pregnant women, not the trained practitioners or state officials, determined who, if anyone, would assist in the deliveries.

This study explores both longitudinal and spatial patterns of deaths that can be attributed directly to childbirth. It reveals that pockets of resistance to academic medicine existed well into the 1880s in some parishes of the Sundsvall region even though the number of midwives increased. Many women continued to consult unlicensed help-women despite the efforts of state officials and local physicians and parish officials to eliminate them as a source of competition to parish midwives.

The Swedish state had a long history of recruiting parish priests, bell-ringers, vaccinators and midwives to assist doctors serving the medical needs of its citizens. The duties and responsibilities of each of these groups were closely regulated. We are often presented with the image of a well-oiled medical machine that gradually displaced folk healers and their cures with licensed practitioners and scientifically proven treatments. ${ }^{6}$ Midwives were instrumental to this transformation as their roles extended far beyond the provision of obstetrical care but this process of supplanting traditional medicine with that of doctors and midwives was not completed until the twentieth century. ${ }^{7}$ What remains to be seen is the degree to which academic medicine was able to extend its grip into the remote villages and affect the behaviour of the women living there during the later 1800s. Even in 1900 more than 20 per cent of women delivered their children at home without the assistance of a doctor or trained midwife, and less than 3 per cent gave birth in an institution. ${ }^{8}$ These figures suggest that these women were not as easily manipulated as we might be led to expect.

We might also look to the annual reports that local physicians submitted to the authorities in Stockholm as further evidence of the persistence of traditional healers well into the nineteenth century. In 1873, Dr Baggstedt, the district physician for the rural parishes of the Sundsvall region, discovered numerous quacks and folk healers working throughout the area. This did not seem to upset him unduly suggesting that these men and women were an expected and rather common feature of rural Swedish life. ${ }^{9}$ Many continued to have a loyal following into the 1880 s thereby proving that doctors had not entirely displaced them.

\footnotetext{
${ }^{6}$ One of the most thorough investigations of the workings of the Swedish medical authorities involves an analysis of the organization of the smallpox vaccination campaign. Peter Sköld, The two faces of smallpox: a disease and its prevention in eighteenthand nineteenth-century Sweden, Umeå, Demographic Data Base, 1996, pp. 383-99. This campaign was undoubtedly successful but it would be a mistake to view all initiatives launched by the state in such a positive light.

${ }^{7}$ For a thorough discussion of midwives' responsibilities see, Christina Romlid, Makt, motstaind och förändring: Vårdens historia speglad genom det
}

svenska barnmorskeväsendet 1663-1908, Stockholm, Forskning och Utveckling, Vårdförbundet, 1998, pp. 197-204.

${ }^{8}$ Signild Vallgårda, 'Hospitalization of deliveries: the change of place of birth in Denmark and Sweden from the late nineteenth century to 1970 ,' Med. Hist., 1996, 40: 173-90, p. 177; U Högberg, S Wall and G Broström, 'The impact of early medical technology on maternal mortality in late 19th-century Sweden', Int. J. Gynecol. Obstet., 1986, 24: 251-61, p. 256.

${ }^{9}$ Riksarkivet (hereafter RA), Sundhets Collegium, Series E5A, vol. 43, Report No. 224, 'Årsberättelser för Sundsvalls District för År 1873'. 


\section{Stephan Curtis}

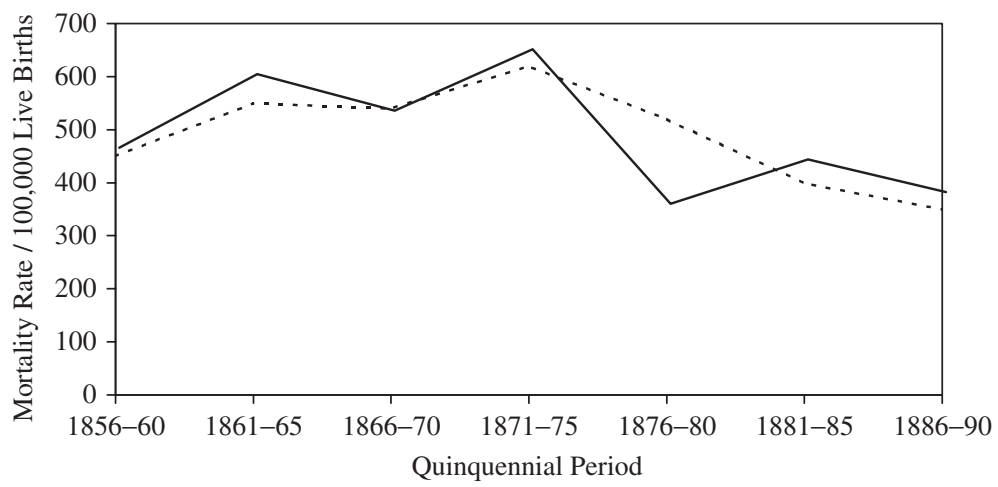

-Sundsvall Region - - - - - Sweden

Figure 1: Mortality from direct obstetric causes in Sweden and the Sundsvall region, 1856-1890.

Sources: Demographic Data Base (Umeå, Sweden); E W Wretlind, 'Döde af barnsängsfeber och barnsbörd i Sverge 1776-1900', Jordemodern, 1904, 17: 21-7.

Despite their relatively ubiquitous presence in the Sundsvall region, it is extremely difficult to determine their ability to delay the acceptance of trained medical practitioners and their medicine. Unlicensed healers usually moved quite frequently throughout the parishes and this made it almost impossible for nineteenth-century doctors to determine the size of their clientele.

Sweden enjoyed an enviably low maternal mortality rate compared with that of other European countries. For the country as a whole these rates fell from approximately 780 per 100,000 live births between 1801 and 1805 to about 230 per 100,000 in 1900. By way of comparison, maternal mortality rates in England and Wales remained at almost 480 per 100,000 live births as late as $1900 .{ }^{10}$ Despite this general pattern of quite remarkable decline, the increase in maternal mortality from approximately 1860 to 1880 that peaked in the early 1870s indicates that this reduction was subject to quite dramatic, albeit often short-lived, reversals. ${ }^{11}$ It is these periods when maternal mortality rates rose, or at least did not continue to fall, that highlight the error in ascribing monocausal explanations such as a greater provision of midwives to general trends.

Figure 1 illustrates the substantial reduction in mortality due only to direct obstetric causes that occurred in the Sundsvall region and Sweden during the latter half of the nineteenth century. ${ }^{12}$ National trends and those for the Sundsvall region moved in unison from almost 460 deaths per 100,000 live births in the late 1850 s until the early 1870 s at

\footnotetext{
${ }^{10}$ Irvine Loudon, Death in childbirth: an international study of maternal care and maternal mortality, 1800-1950, Oxford, Clarendon, 1992, pp. 542-3.

${ }^{11}$ Ulf Högberg and Stig Wall, 'Secular trends of maternal mortality in Sweden for the years 1750-1980',
}

in Ulf Högberg (ed.), Maternal mortality in Sweden, Umeå University, 1985, pp. 29-34, on p. 30.

${ }^{12}$ Figures for nineteenth-century maternal mortality in Sweden include only deaths that are now classified as direct obstetric deaths. Ibid. 


\section{Midwives and their Role in the Reduction of Direct Obstetric Deaths}

which time they rose to almost 640 per 100,000. Beginning in the late 1870 s the mortality rate from these causes in the Sundsvall region fell substantially before rising again in the early $1880 \mathrm{~s}$. In contrast, the national maternal mortality rate followed a more gradual and constant decline from 1875 to 1890 . The maternal mortality rate for all of Sweden was about 350 per 100,000 and was only marginally higher for the Sundsvall region by the turn of the century. ${ }^{13}$

\section{Methods and Sources}

This study examines maternal mortality from direct obstetric causes during the late nineteenth century only in the rural parishes of the Sundsvall region and not in the town itself. It tests the assumption that the state was able to extend the influence of academic medicine into the countryside by improving the access to trained midwives. There are several reasons for focusing attention on the town's hinterland. While it is true that both Sundsvall and neighbouring parishes witnessed an increase in the number of midwives, the use of traditional healers and help-women was most often reported in the countryside. Second, it is unlikely that the geographical distance between urban midwife and woman in labour would have played any significant role in determining whether the parturient would choose to be delivered by a midwife or not. One of the purposes here is to examine whether the decisions made by rural women to call a midwife were in some degree partially determined by their proximity to her. The strongest reason for studying the town's hinterland rather than the town itself is to emphasize both the need for more studies of rural mortality and to deflect attention away from the public health measures that almost all urban centres witnessed during the later nineteenth century. ${ }^{14}$ There is little doubt that the power and influence of the state and local physicians was most evident in the towns and cities. The question is to what degree their influence extended into the hinterland. This is a particularly important question when we remember that the population of nineteenthcentury Sweden was overwhelmingly rural.

The relatively few cases included in this study make the findings largely tentative and statistical analysis relatively impossible. Despite these limitations this example will help illuminate why it is necessary to recognize the influence of traditional cultures when attempting to reduce maternal mortality in underdeveloped parts of the world. It is this, rather than the determination of local and national governments, that best explains the eventual success such campaigns had in the past and will have in the future.

The study of maternal mortality is complicated by the diseases and the length of the postpartum period to be included in the definition. ${ }^{15}$ The International Classification of Diseases distinguishes between four types of death that contribute to the total maternal mortality rate: direct and indirect obstetric deaths, pregnancy-related deaths, and late maternal

\footnotetext{
${ }^{13}$ Files from the Demographic Data Base (hereafter DDB); E Wretlind, 'Döde af barnsängsfeber och barnsbord i Sverige 1776-1900', Jordemodern, 1904, 17: 21-7, p. 23.

${ }^{14}$ For an excellent study of mortality in the town of Sundsvall, see Sören Edvinsson, Den osunda staden: sociala skillnader $i$ dödlighet $i$ 1800-talets Sundsvall, Umeå, Demographic Data Base, 1992.
}

\footnotetext{
${ }^{15}$ Loudon points out that although most women die in the postnatal period, there is no uniform definition of how long this is. Loudon, op. cit., note 10 above, p. 21. See also, Y Berhane, T Andersson, S Wall, P Byass, U Högberg, 'Aims, options and outcomes in measuring maternal mortality in developing societies,' Acta Obstet. Gynecol. Scand., 2000, 79: 968-72, pp. 968-9.
} 


\section{Stephan Curtis}

deaths. ${ }^{16}$ It is only those identified as "direct obstetric deaths", i.e. those that were an obvious result of obstetric complications, that are of interest here because it is these that we can assume a trained midwife would have been most able to prevent. ${ }^{17}$ Her responsibility for deaths due to diseases contracted during pregnancy and exacerbated by childbirth (indirect obstetric deaths) is less clear. Similarly, the further we move temporally from the moment of birth the less we can hold the medical practitioner, whether doctor, midwife, traditional healer, or help-woman, responsible for the woman's eventual demise.

Obviously the longer the period between the end of pregnancy and the death of the mother is extended, for example up to one year, the more cases can be included under the rubric of maternal mortality. Ideally this study would include all deaths among new mothers who died while pregnant and within 42 days of the termination of pregnancy (pregnancy related deaths) as this is the current norm for defining maternal mortality. To do so would have the advantage of making these findings somewhat more comparable to contemporary studies of developing countries. Although this may be the most common periodization, Roger Schofield reports that the period included in studies of maternal mortality ranges from 30 to 60 days. ${ }^{18}$ The advantages gained from increasing the number of cases are offset by the greater uncertainty that accompanies associating the pregnancy and childbirth with the mothers' deaths. This is particularly true in a socio-economic environment where infectious diseases were rampant, living conditions deplorable, the status of women unequal to that of men, and access to effective medical care unlikely. Simply stated, far too many circumstances other than those associated with childbirth could so dramatically weaken a mother's resistance to disease that it is dangerous to ascribe her much delayed death to the consequences of her child's delivery.

To avoid such uncertainty this paper focuses solely on the 213 of 232 deaths among Sundsvall women aged 15 to 45 who died as a direct result of childbirth and for whom there is complete data. As such, they represent only the group of direct obstetric deaths that Tobias Andersson, Staffan Bergström and Ulf Högberg describe. ${ }^{19}$ Admittedly, using only these deaths introduces some bias into the results, as we can assume from the diagnosis that a doctor or midwife determined the cause of death. Therefore, this analysis considers only those births that a trained medical practitioner either attended or had first-hand knowledge of. These women are recorded in the parish death registers as having died from puerperal fever, peritonitis puerperalis, sepsis puerperalis, placenta praevia, miscarriage (missfall), or difficult childbirth (svår barnsbörd). Despite this limitation, it is reasonable to assume that they represent no less than 30 per cent, and perhaps as much as 50 per cent of all maternal deaths. ${ }^{20}$

\footnotetext{
${ }^{16}$ These categories are summarized in T Andersson, S Bergström, and U Högberg, 'Swedish maternal mortality in the 19th century by different definitions: previous stillbirths but not multiparity risk factor for maternal death,' Acta Obstet. Gynecol. Scand., 2000, 79: 679-86, p. 681.

${ }^{17}$ For example, in addition to the use of antisepsis, midwives could also have reduced the likelihood of post-partum haemorrhage by hastening the expulsion of the placenta.

${ }^{18} \mathrm{R}$ Schofield, 'Did the mothers really die? Three centuries of maternal mortality in "the world
}

we have lost", , in L Bonfield, R M Smith, and $\mathrm{K}$ Wrightson (eds), The world we have gained: histories of population and social structure, Oxford, Basil Blackwell, 1986, pp. 231-60, on p. 234.

${ }^{19}$ Andersson, Bergström, Högberg, op. cit., note 16 above, p. 681.

${ }^{20}$ Ibid. This estimate is based on studies examining maternal mortality throughout the nineteenth century. U Högberg and G Broström, 'The demography of maternal mortality: seven Swedish parishes in the 19th century', in Högberg (ed.), op. cit., note 11 above, pp. $37-44$, p. 39. 


\section{Midwives and their Role in the Reduction of Direct Obstetric Deaths}

Normally we would expect to find numerous deaths from haemorrhage as a result of childbirth. Their absence suggests that they were classified as something else; it appears that they were included under the rubric of difficult childbirth in the parish death records. Unfortunately, it is impossible to garner any information regarding the specific causes of death ascribed to this broad category. Only one woman aged between 15 and 45 died from haemorrhage during the entire period 1860-90, according to the parish death registers. For that individual there was no indication of a child having ever been born. An investigation of deaths ascribed to the vaguely defined term "bleeding" provides no possible additional cases of post-partum haemorrhage. ${ }^{21}$

The majority of the women who died were between the ages of 25 and 34 and of those for whom accurate information is available, 85 per cent $(n=161)$ died within 14 days of giving birth. Another 15 per cent $(n=28)$ died between 15 and 39 days, and for the remaining 24 cases there is no information available regarding the interval between the birth of the last child and the mother's death. The occupations of these women reflect Sundsvall region's rapid economic transformation from agriculture to industry. Most were identified as maids ( 9 per cent), or wives of cottagers (10 per cent), farmers (14 per cent), or workers (28 per cent). ${ }^{22}$

The problem of retrospective diagnosis confounds the historian seeking to identify historical mortality patterns. Not only are many of the alleged causes of death so remarkably vaguely defined that they defy classification, but also in many instances we cannot be certain the doctor or midwife identified the cause of death correctly. Even if a physician was present at his patient's death, something that was all too frequently not the case, he occasionally had his own reasons for deliberately obscuring the real cause of death. ${ }^{23}$ More often than not, however, the uncertainty that many of these physicians' diagnoses cause us today was less due to deliberate obfuscation or ignorance than the limitations of nineteenthcentury medicine. Our knowledge is also dependent upon the ability of these men and women to discern the most proximate cause of death from the many conditions that frequently conspired to steal the life of the sick. This is seldom an easy task for a physician today. In an era when medical conditions were seldom understood, and the doctor often unfamiliar with the patient he was treating, trying to determine the primary cause of death could pose a considerable challenge. However, despite all these caveats, it is likely that most deaths from puerperal fever or complications arising from childbirth were accurately diagnosed. $^{24}$

\footnotetext{
${ }^{21}$ This group included "blood flow, vomiting blood, burst vein/artery, and haemorrhage". DDB files.

${ }^{22}$ DDB files.

${ }^{23}$ Loudon identifies this problem of hidden maternal deaths and states that they could easily account for an additional 20 per cent of maternal deaths during the nineteenth century. The deliberate obscuring of maternal deaths caused by incompetence would likely have been highest after the introduction of antisepsis in the 1880 s that dramatically reduced the risk to the new mother. Loudon, op. cit., note 10 above, pp. 34-7.
}

For a discussion of the possible implications of changing cause-of-death classifications in Sweden see, Högberg and Wall, op. cit., note 11 above, pp. 29-30.

${ }^{24}$ Verbal autopsies conducted in under-developed countries of today when death appears to have been the result of childbirth have proved quite reliable. There is no reason to believe that nineteenth-century Swedish doctors or midwives would have had any more difficulty determining the cause of death using a similar strategy. Ulf Högberg, personal communication 16 Oct. 2003. 


\section{Stephan Curtis}

Another problem facing the researcher lies in the composition of the most readily accessible data. Aggregate statistics by their nature obscure wide regional differences. Before we claim a decisive victory for academic medicine we would be wise to look beyond those figures indicating a secular and nationwide decline in Swedish maternal mortality during the nineteenth century. Andersson finds that not only did the pattern of maternal mortality in the Sundsvall region differ from that of the country as a whole, it also varied within the region itself. For example, it was higher in the town of Sundsvall and those parishes most dependent upon the sawmill industry than in the more rural parishes. ${ }^{25}$ Several factors ranging from the persistence of traditions that involved using untrained women (kloka gummor) to help deliver children, to the more pragmatic problem of finding a nearby trained midwife who could assist if needed, certainly go a long way to explaining regional patterns of maternal mortality, but other explanations must also be considered. In the Sundsvall region the process of industrialization and the growth of the town both contributed to the rise and eventual decline of maternal mortality. On the one hand, these processes exposed new mothers to the unhealthy conditions that characterized such environments. On the other hand, by the latter part of the century the town probably helped improve the health of those living in nearby parishes by acting as a gateway through which new medical information and techniques arrived and were disseminated into the interior.

Computer files constructed by the Demographic Data Base (DDB) in Umeå, Sweden, from parish registers and other sources provide the quantitative information necessary for this study. Additional sources include the annual reports that district physicians submitted to the authorities in Stockholm. These provide invaluable information about the major characteristics of these parishes such as the disease panoramas, the local economy and, by the later 1800 s, fairly lengthy discussions regarding the state of midwifery in the various parishes. The DDB's internet database 'Indiko' offers additional information garnered from parish registers and other sources about the residence patterns of midwives and the family history of the women studied here.

\section{The Sundsvall Region}

The Sundsvall region of Västernorrland consists of sixteen parishes located approximately 350 kilometres north of Stockholm and encompasses an area of more than 2,600 square kilometres. For the purposes of this study, the parishes that constituted the Sundsvall region have been divided according to their geographical location (coastal or inland), and their dominant economic character (industrial, agricultural, or economically mixed). See Maps 1 and 2.

A booming lumber industry, particularly from 1870 onwards, made the need for additional doctors and midwives much more acute than had been the case earlier in the century. A flood of in-migrants who entered the region while the sawmills were in operation greatly strained the ability of these practitioners to tend the sick. Many workers and their families initially stayed only while the rivers were free of ice and the sawmills were working at full

\footnotetext{
${ }^{25}$ Sam Willner, Det svaga könet? Kön och vuxendödlighet i 1800-talets Sverige, Linköping University, 1999, p. 107; T Andersson, Survival of
}

mothers and their offspring in 19th-century Sweden and contemporary rural Ethiopia, Umeå University, 2000, pp. 22-3. 


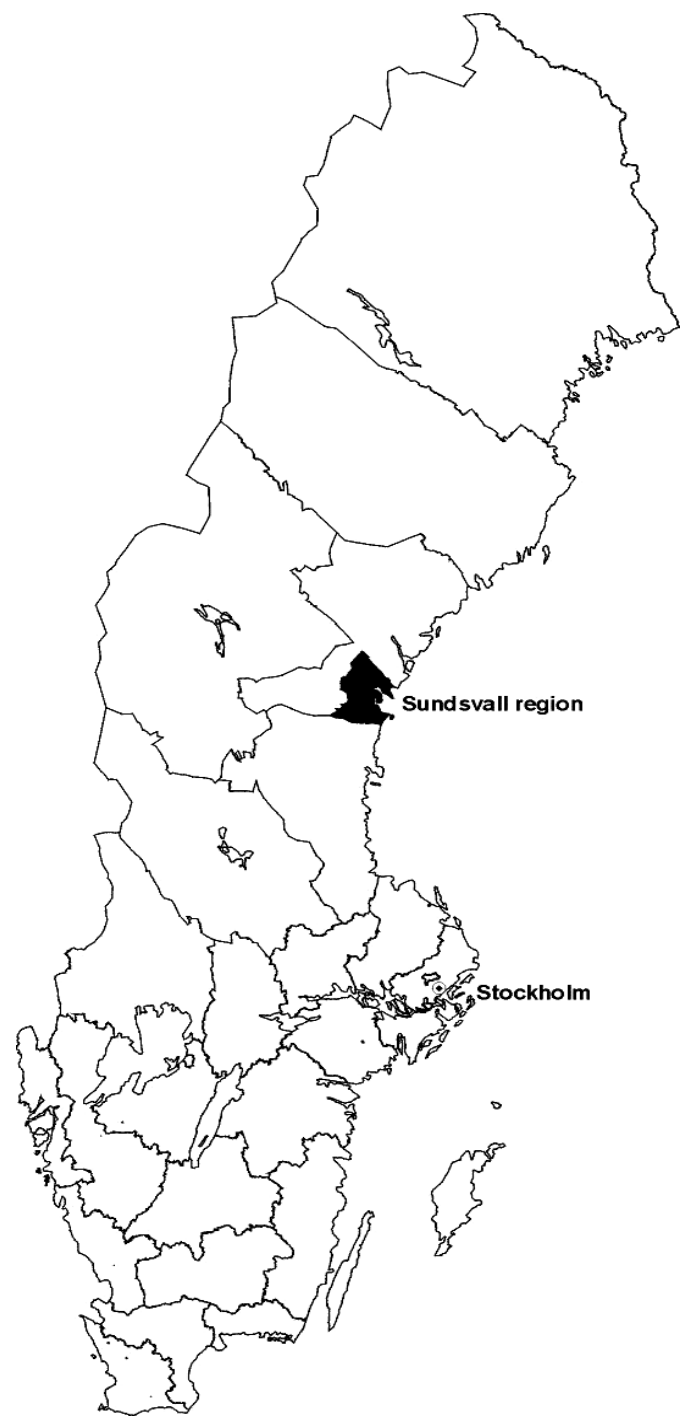

Map 1: Sweden, showing the location of the Sundsvall region

Source: Demographic Data Base (Umeå, Sweden).

capacity. As the opportunity for more permanent work increased, a high proportion of these men and women moved permanently into the coastal parishes where the mills were located. Most of these inhabitants lived in the abysmal conditions that local doctors frequently condemned in their annual reports to the authorities in Stockholm. ${ }^{26}$

${ }^{26}$ See, for example, RA, Sundhets Collegium, Series

E5A, vol. 40, annual report from Wifstavarf, 1870. 


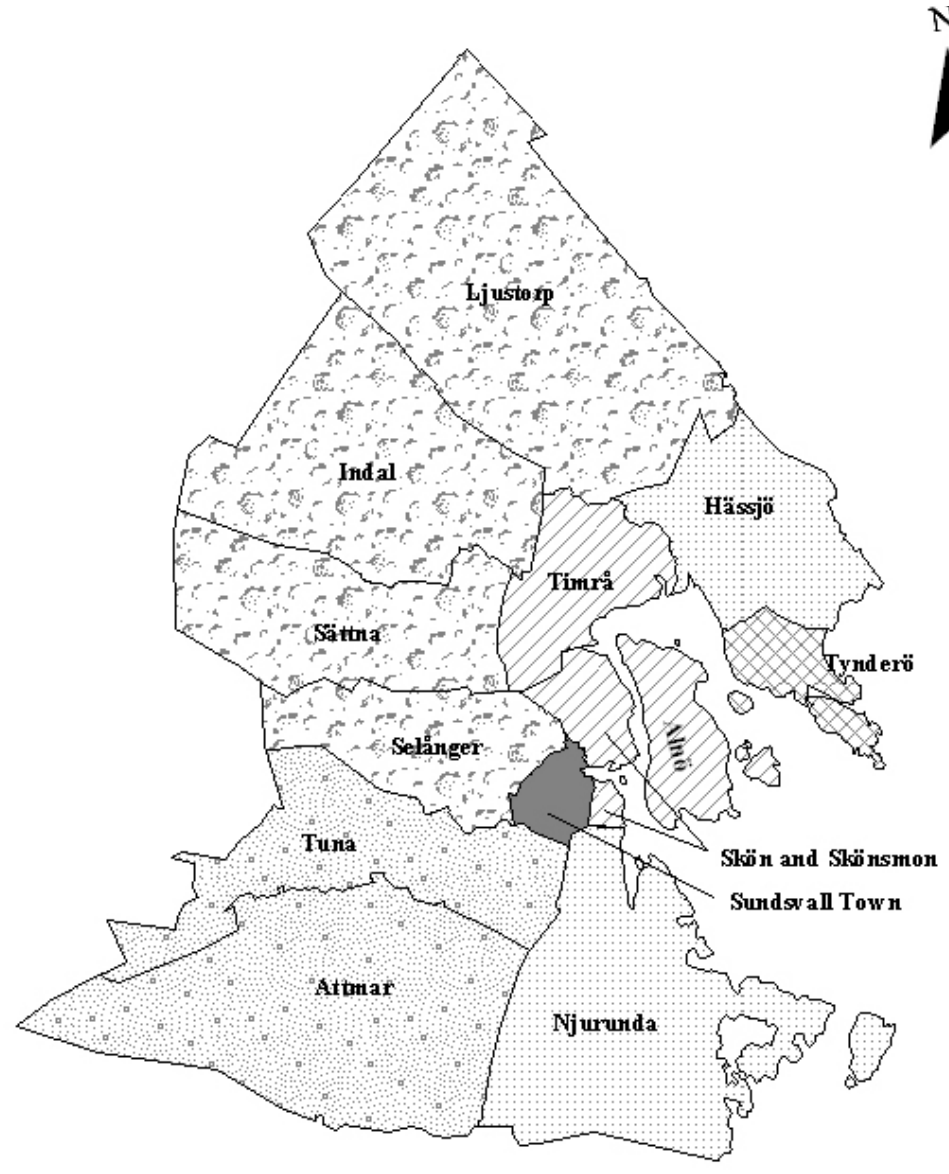

\section{Parish Location and Economic Structure}

parish boundaries

20 Coastal agricultural

Coastal economically mixed

7 Coastal industrial

E*a. Inland agricultural

In: Inland economically mixed

Urban

Map 2: The location and economic characteristics of the Sundsvall parishes 


\section{Midwives and their Role in the Reduction of Direct Obstetric Deaths}

\section{The Campaign to Reduce Maternal Mortality}

Throughout the 1800s the Swedish state introduced an array of measures aimed at reducing infant mortality and improving the level of care available to new mothers. Midwives were an integral part of this strategy. ${ }^{27}$ Their responsibility for providing medical care in much of nineteenth-century Sweden was particularly evident in parts of the country where there were few physicians and the population was widely dispersed. As early as 1829 midwives who completed their six months of basic training and an additional threemonth course were allowed to use birthing instruments such as forceps, sharp hooks and perforators if a doctor was unavailable. In 1840 their instruction was extended to nine months with an additional three months of training in the use of instruments. ${ }^{28}$ Legislation passed in 1860 even permitted midwives to declare the cause of death if their efforts to save the infant and/or mother were unsuccessful. ${ }^{29}$ In addition to relative autonomy from constant supervision, Swedish midwives also enjoyed a complementary rather than competitive existence with local physicians. Although there was some competition for patients in Stockholm, there was a remarkable lack of animosity between doctors and midwives in rural Sweden. ${ }^{30}$ This relationship stood in stark contrast to the antagonism that existed elsewhere in Europe. For example, as late as the mid-1890s numerous British physicians adamantly opposed granting midwives any independence and worked to remove them from the medical world entirely. ${ }^{31}$

Among the major causes of maternal death in the nineteenth century, puerperal fever stands out as the leading scourge. It was a major concern among officials at the Sundhets Collegium and its successor the Medicinalstyrelsen for good reason. Deaths from puerperal fever increased so markedly between 1861 and 1874 that they more than compensated for the decline in maternal mortality from other causes. The result was an actual increase in total maternal mortality for this period. It appears likely that the dominance of a particularly virulent strain of streptococcus was responsible for this sudden increase in deaths. Similar peaks occurred throughout much of Sweden, and in Norway and Britain. ${ }^{32}$ As Högberg, Wall and Broström argue, it is also possible that this upsurge was more apparent than real and may have been due to a change in how causes of death were recorded. Högberg and his co-authors also suggest that a gradual decline in living standards, at least in the Swedish parishes they studied, was partially responsible for the increase. Whatever the cause, puerperal sepsis accounted for 51 per cent of all maternal deaths for the period 1861-90. ${ }^{33}$

\footnotetext{
${ }^{27}$ These measures included courses in basic childcare and the treatment of childhood diseases as part of midwives' training. Anders Brändström,

"De kärlekslösa mödrarna": spädbarnsdödligheten $i$ Sverige under 1800-talet med särskild hänsyn till Nedertornea ${ }^{\circ}$, Umeå University, 1984.

${ }^{28}$ Vallgårda, op. cit., note 8 above, p. 183; Romlid, op. cit., note 7 above, pp. 291-2.

${ }^{29}$ Lennart Nordenfelt, B Ingemar, and B Lindahl, Om grunden för svensk dödsorsaksstatistik, Linköping, Department of Health and Society, University of Linköping, 1984, pp. 4-5, cited in Christina Romlid, 'The Swedish maternal mortality rate in the nineteenth century', unpublished paper, Uppsala University, p. 3.

${ }^{30}$ Compare Lisa Öberg, Barnmorskan och läkaren: Kompetens och konflikt $i$ svensk förlossningsvaird
}

1870-1920, Stockholm, Ordfronts, 1996, with Romlid, op. cit., note 7 above. Although both authors discuss the tensions that existed between doctors and midwives, it was less pronounced the farther one moved from the major cities. See also Ulf Högberg,

'The decline in maternal mortality in Sweden: the role of community midwifery', Am. J. Public Health, 2004, 94: $1312-20$.

${ }^{31}$ Jean Donnison, Midwives and medical men: a history of inter-professional rivalries and women's rights, London, Heinemann Educational, 1977, pp. 113, 134.

${ }^{32}$ Loudon, op. cit., note 10 above, p. 412.

${ }^{33}$ Högberg, Wall, and Broström, op. cit., note 8 above, pp. 252, 254, 258. 


\section{Stephan Curtis}

On 13 June 1881 a circular was distributed to all midwives providing detailed instructions for preventing the disease and what to do should it occur. They were directed to follow the necessary precautions such as sterilizing their hands and instruments with carbolic acid, and using soap to provide as clean a birthing environment as possible. ${ }^{34}$ Only because midwives were required to purchase these items from their own income might their willingness and ability to follow these procedures have been compromised. However, the overwhelming evidence is that the majority of midwives followed the instructions they had been given. Högberg has conducted the most thorough investigation of maternal mortality in Sweden and argues convincingly that the midwives' knowledge of antisepsis in the early 1880 s was directly responsible for the reduction in the number of women who died as a result of childbirth. ${ }^{35}$

The situation in Sweden has been compared with that in Britain by Irvine Loudon to demonstrate the importance of midwives trained in the use of antisepsis to the reduction in mortality from puerperal fever. Both countries witnessed the same peak in puerperal fever mortality in 1874-5 but thereafter the trends differed markedly. The death rate in Sweden fell during the rest of the century, but in Britain, where midwives with the skills of their Swedish counterparts were not available until the early twentieth century, another peak in puerperal fever mortality appeared in the early $1890 \mathrm{~s} .{ }^{36}$ There appears to be little doubt that Swedish midwives played no small role in saving the lives of mothers by the 1880 s, but we must still look beyond their considerable skills and consider the circumstances that affected those who needed the midwives' services.

Doctors in the Sundsvall parishes spoke very highly of the skills local midwives exhibited and their respect for these women endured well into the 1880s. There was good reason for their praise. Almost all midwives working in Sundsvall by 1880 had been trained in the use of forceps and sharp instruments, such as the hooks and perforators used to extract the foetus if all other methods failed and the life of the mother was in danger. Although almost all midwives in the Sundsvall region had received such training, the percentage of skilled midwives in Västernorrland as a whole fell steadily from 1870 to 1880 . At the beginning of the decade almost 90 per cent of Västernorrland's midwives were so educated but by 1880 this was true for only 77 per cent. ${ }^{37}$

The expertise that Swedish midwives possessed is evident in their reluctance to employ forceps and sharp birthing instruments. At the national level forceps were used only a total of 4,890 times and sharp instruments 135 times between 1877 and $1886 .{ }^{38}$ Högberg et al. record that most midwives would use forceps only once in every 133 to 180 deliveries, and perforators and sharp hooks once in every 3,000 to 4,000 deliveries. ${ }^{39}$ Daybooks from

\footnotetext{
${ }^{34}$ Härnösand Landsarkiv (hereafter H-sand), Första Provincialläkaren i Vasternorrlands län, Series D III, 'Barnmorskors dagböker', "Kongl. Medicialstyrelsens cirkulär till barnmorskorna i riket, angående försigtighetsmått, som böra af dem iakttagas till förekommande utfärdadt den 13 Juni 1881."

${ }^{35}$ Högberg, Wall, Broström, op. cit., note 8 above, p. 254. See also Loudon, op. cit., note 10 above, p. 412; and idem, 'Maternal mortality in the past and its relevance to developing countries
}

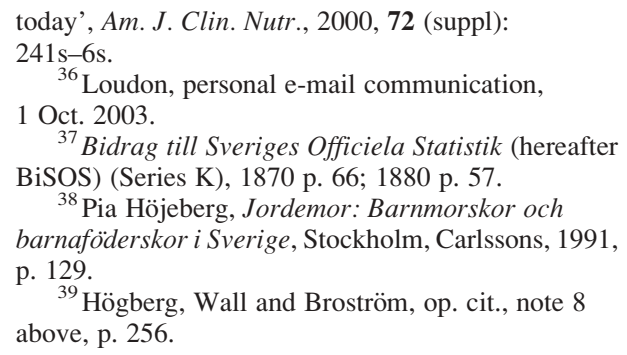




\section{Midwives and their Role in the Reduction of Direct Obstetric Deaths}

six midwives working in the Sundsvall area during the 1880s reveal only thirteen reported the use of birthing instruments among almost 2,000 births attended. In 1884 there were only eight cases in the entire Sundsvall district during which midwives used such instruments in delivering a child. However, some daybooks no longer exist, and the total number of instrument-assisted births was surely higher than the thirteen mentioned here. For example, in 1883 alone the physician responsible for the Sundsvall parishes recorded eight births during which forceps had been used. Still, this accounts for only one-tenth of the total number of births in that year. Similarly, in 1885, a mere 9 of the 1,700 births that had taken place involved the use of instruments. Only once did the district physician question the ability of the midwife concerned. ${ }^{40}$

This one exception involved the midwife Anna Westerlund who had been called to deliver Catharina Granström's son on 8 May 1884. There is some confusion regarding whether instruments were used during the birth. In the report Westerlund forwarded to the district physician, Dr Söderbaum, she stated that the weakness of the mother and her fear for the infant's life had prompted her to use forceps. This resulted in the successful delivery of the child seven minutes later although the mother died after eight days of "stomach inflammation". ${ }^{41}$ However, Westerlund indicated in her own daybook that the birth had been a natural one. ${ }^{42}$ Whatever the case, Söderbaum's notations dealt solely with Granström's death, which seemed to have been the direct result of the birth. Söderbaum questioned Westerlund about the case and she denied any responsibility for the fatal outcome. This was sufficient for Söderbaum, who did not pursue the matter further although the circumstances surrounding Granström's death were suspicious to say the least. ${ }^{43}$ Possibly the doctor simply based his diagnosis on information the midwife provided, or there may have been a deliberate attempt to exonerate the midwife. The fact that the mother died so shortly after the birth of her son and from inflammation and fever certainly suggests that Westerlund may not have been entirely blameless. Yet, even if she contributed to the death of Granström, this one case certainly does not prove that the midwives working in the Sundsvall region were uniformly careless or incompetent.

Table 1 compares mortality rates from direct obstetric causes for different parish groups in the Sundsvall region for the decades 1860-69, 1870-79, and 1880-89. Figures for the coastal-industrial parish of Tynderö have been omitted because of the extremely few deaths related to obstetrical causes. ${ }^{44}$ The overall picture is one of gradual improvement in most of the parish groups from the 1860s to the 1880s. This is most evident in the group of coastal industrial parishes of Alnö, Skön and Timrå where the mortality rate from direct obstetric causes fell from almost 79 per 100,000 during the decade 1860-69, to approximately 36 per 100,000 between 1880 and 1889 .

\footnotetext{
${ }^{40} \mathrm{H}$-sand, Förste Provinsialläkare i

Västernorrlands Län, Series D III: daybooks from midwives in Alnö, Attmar, Hässjö, Indal, Njurunda, Selånger, Skön, Sättna, Timrå and Tuna parishes. RA Medicinal Styrelsen, Series E5A, 'Årsberättelser från provinsialläkare', vols 12, 16, reports from Sundvall's provincial physician for 1883 and 1885 .

41 'Maginflammation'. Indiko database, ID No. 844002234.
}

\footnotetext{
${ }^{42} \mathrm{H}$-sand, Förste Provinsialläkare i Västernorrlands Län, Series D III: 2 Skön 'Barnmorske dagböcker', daybook of Anna Westerlund (1 Jan. 1884-24 Nov. 1885).

${ }^{43}$ RA, Medicinalstyrelsen, Series E14A:9 (1884), 'Instrumentförlossningar', Report No. 424 from Anna Westerlund dated 11 May 1884, with comments from Dr Söderbaum.

${ }^{44}$ DDB files.
} 


\section{Stephan Curtis}

\section{Table 1}

Mortality rates from direct obstetrical causes, ratios of women aged between 15 and 45 per midwife 1860-89, and area per midwife, in the Sundsvall region

\begin{tabular}{|c|c|c|c|c|}
\hline \multicolumn{5}{|c|}{$1860-69$} \\
\hline $\begin{array}{l}\text { Location and economic } \\
\text { structure of parishes }\end{array}$ & $\begin{array}{c}\text { Number of direct } \\
\text { obstetric deaths } \\
\text { among women } \\
\text { aged 15-45 }\end{array}$ & $\begin{array}{c}\text { Average annual } \\
\text { mortality from } \\
\text { obstetrical causes } \\
\text { per 100,000 live } \\
\text { births }\end{array}$ & $\begin{array}{l}\text { Women } \\
\text { per midwife }\end{array}$ & $\begin{array}{l}\text { Square km } \\
\text { per midwife }\end{array}$ \\
\hline Coastal industrial & 17 & 78.8 & 491 & 75 \\
\hline Coastal mixed & 7 & 38.9 & 504 & 264 \\
\hline Coastal agricultural & 1 & $\mathrm{n} / \mathrm{a}$ & 226 & 57 \\
\hline Inland mixed & 2 & 14.1 & 1006 & 618 \\
\hline Inland agricultural & 17 & 76.5 & 569 & 401 \\
\hline \multicolumn{5}{|c|}{$1870-79$} \\
\hline $\begin{array}{l}\text { Location and economic } \\
\text { structure of parishes }\end{array}$ & $\begin{array}{c}\text { Number of direct } \\
\text { obstetric deaths } \\
\text { among women } \\
\text { aged 15-45 }\end{array}$ & $\begin{array}{c}\text { Average annual } \\
\text { mortality from } \\
\text { obstetrical causes } \\
\text { per } 100,000 \text { live } \\
\text { births }\end{array}$ & $\begin{array}{c}\text { Women } \\
\text { per midwife }\end{array}$ & $\begin{array}{l}\text { Square km } \\
\text { per midwife }\end{array}$ \\
\hline Coastal industrial & 19 & 37.1 & 402 & 37.5 \\
\hline Coastal mixed & 10 & 46.0 & 446 & 176 \\
\hline Coastal agricultural & 1 & $\mathrm{n} / \mathrm{a}$ & 261 & 57 \\
\hline Inland mixed & 2 & 11.0 & 1270 & 618 \\
\hline Inland agricultural & 28 & 125.6 & 428 & 301 \\
\hline
\end{tabular}

$1880-89$

\begin{tabular}{|c|c|c|c|c|}
\hline $\begin{array}{l}\text { Location and economic } \\
\text { structure of parishes }\end{array}$ & $\begin{array}{l}\text { Number of direct } \\
\text { obstetric deaths } \\
\text { among women } \\
\text { aged 15-45 }\end{array}$ & $\begin{array}{c}\text { Average annual } \\
\text { mortality from } \\
\text { obstetrical causes } \\
\text { per } 100,000 \text { live } \\
\text { births }\end{array}$ & $\begin{array}{l}\text { Women } \\
\text { per midwife }\end{array}$ & $\begin{array}{l}\text { Square km } \\
\text { per midwife }\end{array}$ \\
\hline Coastal industrial & 28 & 36.0 & 448 & 25 \\
\hline Coastal mixed & 12 & 37.4 & 420 & 132 \\
\hline Coastal agricultural & 4 & $\mathrm{n} / \mathrm{a}$ & 146 & 29 \\
\hline Inland mixed & 7 & 33.8 & 664 & 309 \\
\hline Inland agricultural & 11 & 36.0 & 485 & 301 \\
\hline
\end{tabular}

Sources: Files from the Demographic Data Base (Umeå, Sweden), Riksarkivet, Sundhets Collegium and Medicinalstyrelsen, Series E5A. 


\section{Midwives and their Role in the Reduction of Direct Obstetric Deaths}

The pattern becomes less clear once we move beyond the coastal industrial parishes where the sawmills dominated the economy. The two inland economically mixed parishes of Attmar and Tuna had the lowest rate of direct obstetric deaths of any parish group throughout the period $1860-69$, but as the century progressed the mortality rate from these causes rose rather than declined as was the case elsewhere. In the inland agricultural parishes of Indal, Ljustorp, Selånger, and Sättna direct obstetric mortality rates in the 1880 s were much lower than they had been twenty years earlier. However, women living in these parishes during the 1870 s seem to have been particularly vulnerable to death from puerperal fever and difficult childbirth. These parishes recorded the highest mortality rate from these causes of any parish group during the entire study period. ${ }^{45}$ The coastal parishes of Hässjö and Njurunda witnessed only a slight reduction in the mortality rate from direct obstetric causes by the 1880 s compared with the 1860s. As was the case in the inland agricultural parishes, mortality from these causes rose during the 1870 s but to a much smaller degree.

By the 1880s direct obstetric mortality rates were almost identical in all the parish groups suggesting that whatever had prompted the decline in the industrial parishes had also affected the rest of the region. The increasing number of midwives that the state provided probably allowed the influence of academic medicine to reach even the most remote villages of the Sundsvall region. While there is some evidence that this in fact occurred, it does not necessarily mean that the traditional help-woman had disappeared entirely.

\section{The Provision of Midwives in the Sundsvall Region}

From $c .1870$ the government gradually succeeded in increasing the supply of midwives, albeit somewhat variably, as the ratio of females to midwives for Sweden as a whole, the province of Västernorrland, and the Sundsvall region demonstrates. The provision of midwives in the latter compared quite favourably both to the country and to the province for much of the period under investigation (Figure 2). The lone exception was during the early 1870 s when unprecedented economic and demographic growth in the area clearly undermined the state's efforts to provide an adequate number of midwives. Despite this minor reversal there can be no doubt that the overall picture is one of marked improvement. In 1861 each of the region's ten midwives had to attend to the needs of slightly more than 1,400 women. By the early 1890 s the number of midwives had almost tripled and the ratio of females to midwives had fallen to just over 1,000:1. The improvement in the supply of midwives is even more pronounced if the town of Sundsvall itself is examined. In 1860 it had just two midwives for a population of 2,330 females but in 1890 there were ten midwives for the town's 6,700 females. $^{46}$

\footnotetext{
${ }^{45}$ There were 28 deaths between $1870-79$ representing 50 per cent of the 56 deaths between 1860-90. DDB files.

${ }^{46}$ Figures are compiled from BiSoS (Series K), files from the DDB, and the annual reports submitted by local physicians. RA, Sundhets Collegium and
}

\author{
Medicinalstyrelsen, Series E5A, 'Årsberättelser från \\ provinsialläkare’. Unfortunately, information \\ contained in official statistics does not make it \\ possible to calculate the ratio of midwives to \\ women of childbearing age but only to all \\ females.
}




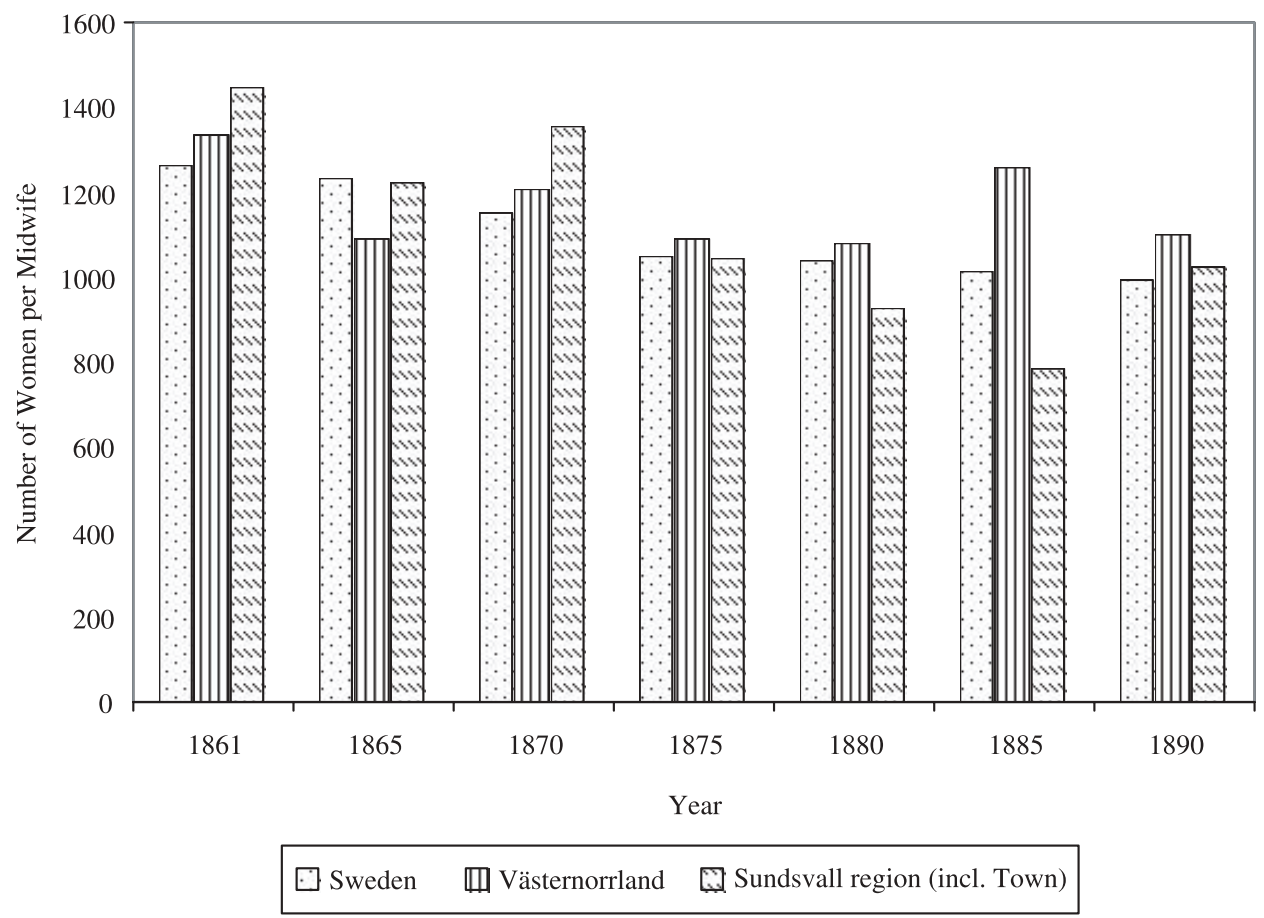

Figure 2: Ratios of females to midwives in Sweden, Västernorrland, and the Sundsvall region, $1861-1890$.

Sources: Demographic Data Base (Umeå, Sweden); Riksarkivet, Sundhets Collegium and Medicinalstyrelsen, Series E5A, 'Årsberättelser från Provincialläkare', reports from Sundsvall and, after 1870, from Wifstavarf district physicians.

The figures offer a positive portrayal of the greater accessibility to the obstetrical care that midwives could provide but this is tempered by the fact that within the Sundsvall region there were wide disparities between groups of parishes. The degree to which conditions varied can be seen both in the ratio of women to midwives, and in the distances each midwife needed to travel to reach parturients calling on her services. The ratio of women to midwives was lowest in those parishes dominated by sawmills. In 1885 there were about 450 women between the ages of 15 and 45 per midwife in this group of coastalindustrial parishes (Table 1). The corresponding ratio in the group of inland economically mixed parishes of Attmar and Tuna was approximately 660:1. ${ }^{47}$

Unequal access to midwives is even more apparent if we use the square area for which each midwife was responsible as an indication of their workload. The distances these women needed to travel to reach the most distant homes could be expected to have greatly restricted the number of births they could attend, and thereby delayed the diffusion of

\footnotetext{
${ }^{47} \mathrm{BiSoS}$, files from the DDB, and annual and Medicinalstyrelsen, Series E5A, ‘ Årsberättelser physicians' reports found in RA, Sundhets Collegium

från provinsialläkare’, for the years 1860-90.
} 


\section{Midwives and their Role in the Reduction of Direct Obstetric Deaths}

academic medicine throughout the countryside. ${ }^{48}$ This should have been particularly true before the development of an established network of roads. However, as we shall shortly see, there is little evidence that midwives were significantly hampered by distance from helping women who sought their services.

Midwives in the Sundsvall region frequently overcame the obstacles that large distances presented and attended a higher percentage of births than the 40 per cent achieved by their counterparts in many other parts of the country in the $1860 \mathrm{~s} .{ }^{49}$ Again, however, there were wide discrepancies among the different groups of parishes. Midwives in those dominated by agriculture attended fewer than 30 per cent of all births in 1861. Four years later, the midwife responsible for Sättna parish, Cajsa Sundqvist, attended a paltry 16 per cent of the 56 births that occurred during the year. Unlicensed practitioners attended the remaining births, or the mothers delivered their infants themselves. ${ }^{50}$ Unfortunately there is no way of knowing. What we can be quite sure of is that it was highly unlikely that these women had their infants delivered in an institution. Even as late as 1895 less than 3 per cent of all births in Sweden occurred in a lying-in hospital. ${ }^{51}$

The case of Sättna was certainly an extreme example. Sundqvist was then sixty years old and this may have impaired her ability to reach some of the more remote parts of the parish. It is more likely, however, that this case illustrates the degree to which traditional healers and help-women continued to dominate the provision of obstetrical care in some rural areas. According to the provincial physician, Sundqvist was also responsible for Timrå parish and there she, or perhaps midwives living in the nearby town, attended at least 64 per cent of all births. ${ }^{52}$

The markedly different midwife attendance rates in these two parishes illustrates either what doctors claimed was an impenetrable wall of traditional ignorance and culture, or the gradual advances of academic medicine. The provincial physician certainly painted Sättna as a bastion of conservatism as late as 1874 , and attributed the persistence of old customs as one of the major obstacles to providing better care to new mothers. The fact that Sundqvist was now seventy years old was probably an equally serious impediment to the spreading of new obstetrical methods and this encouraged the doctor to seek a younger replacement. ${ }^{53}$

The alleged backwardness among inhabitants living in Sättna parish contrasted sharply with the more progressive attitudes found in Timrå. The question remains why behaviour in the two parishes differed so noticeably. The expansion of Timrå's sawmill industry and the concomitant growth of sickness insurance plans at the mills may have been partially responsible for the gradual acceptance of academic medicine, but not until the 1870 s

\footnotetext{
${ }^{48}$ In a recent study of modern Zambia, distance was found to be one of the key factors preventing women from accessing medical care. It is unlikely that long distances would not also have deterred women from seeking medical help in the Sundsvall region during the nineteenth century. F Le Bacq and A Rietsema, 'High maternal mortality levels and additional risk from poor accessibility in two districts of Northern Province, Zambia', Int. J. Epidemiol., 1997, 26: 357-63.

${ }^{49}$ Rural midwives in Sweden attended approximately thirty-seven births per year during the
}

second half of the nineteenth century. Högberg, Wall and Broström, op. cit., note 8 above, p. 256.

${ }^{50}$ Thanks to Sören Edvinsson at the DDB for making this information available to me.

${ }^{51}$ Högberg, Wall and Broström, op. cit., note 8 above, pp. 255-6.

${ }^{52}$ Although parish birth records often indicate whether a midwife had attended a birth, they do not show which specific midwife was in attendance.

${ }^{53}$ RA, Sundhets Collegium, Series E5A, 'Årsberättelser från provinsialläkare', vol. 44, report from Sundsvall's provincial physician for 1874 . 


\section{Stephan Curtis}

Table 2

Percentage of births attended by midwives in selected parishes of the Sundsvall region (1884-7)

\begin{tabular}{lcccc}
\hline & 1884 & 1885 & 1886 & 1887 \\
\hline Sättna & 80 & 80 & 87 & 74 \\
Njurunda & n/a & 90 & 94 & 87 \\
Tuna & 63 & 56 & 61 & 83 \\
Indal & 75 & 59 & 71 & 68 \\
Attmar & 47 & 44 & 59 & 54
\end{tabular}

Source: Riksarkivet, Medicinalstyrelsen, Series E5A, 'Årsberättelser från provinsialläkare', vols. 14, 16, 18 and 19, reports from the Sundsvall district physician.

at the earliest. It is more likely that the parish's proximity to the town played a significant role in changing the behaviour of new mothers. Timrå's residents certainly would have been more easily exposed to the numerous physicians and midwives living in and around the town than people living in the more distant parish of Sättna.

Between 1882 and 1887, Elisabeth Holmgren, the midwife for the inland parish of Tuna, attended approximately 55 births annually, representing about 50 per cent of all births. ${ }^{54}$ It seems that this was well below the average for the area. ${ }^{55}$ Sundsvall's district physician, Dr Söderbaum, reported that for most of the parishes under his supervision midwives attended 65 per cent of all births in $1884 .{ }^{56}$ Five years later the number of births in his district skyrocketed to almost 800 but the midwives had been called to more than 80 per cent of them. This was well above the national average of approximately 70 per cent of all home deliveries that midwives attended in $1890 .^{57}$

One of the busiest of the Sundsvall midwives must have been Anna Westerlund of Skön parish, who attended almost 120 births every year between 1882 and $1886 .{ }^{58}$ In some underdeveloped countries today we can assume that a midwife is able to attend and provide post-natal instruction for approximately 150 births annually. ${ }^{59}$ To achieve so comparable a number in the rugged terrain of the Sundsvall region during the nineteenth century would have required a substantial effort.

During the mid-1880s midwives also made inroads into some of the parishes for which the Sundsvall district physician was responsible (Table 2). There are, however, no comparable figures available for the industrial parishes. Even during this period, when the

\footnotetext{
${ }^{54}$ The number of births attended is found in $\mathrm{H}$-sand, Förste Provinsialläkarens i Västernorrlands län, Series D III:I, 'Barnmorskors dagbocker-Tuna'. The total number of births in the parish is supplied by the 'Birth file' constructed by the DDB.

${ }^{55} \mathrm{H}$-sand, Förste Provinsialläkarens i Västernorrlands län, Series D III:I, 'Barnmorskors dagbocker-Skön'. DDB files provide the total number of births in this parish.

${ }^{56}$ RA, Medicinalstyrelsen, Series E5A, ‘Årsberättelser från provinsialläkare', vol. 14, Report No. 114 from Dr Söderbaum in Sundsvall.
}

He reported that there had been a total of 450 births in the parishes for which he was responsible.

${ }^{57}$ RA, Medicinalstyrelsen, Series E5A,

‘Årsberättelser från provinsialläkare', vol. 24, Report No. 248 from Dr Söderbaum in Sundsvall. Högberg, Wall, and Broström, op. cit., note 8 above, p. 255.

${ }^{58} \mathrm{H}$-sand, Förste Provinsialläkarens i

Västernorrlands län, Series D III:I, 'Barnmorskors dagbocker-Skön'.

${ }^{59}$ Walraven and Weeks, op. cit., note 2 above, 


\section{Midwives and their Role in the Reduction of Direct Obstetric Deaths}

transition from traditional to more academic medicine seemed to be well on the way, considerable resistance remained in some parts of the region. For example, Johanna Petersson, the parish midwife for Attmar, attended only about one-half of all births. At the other extreme, the three midwives who worked in Njurunda were called to almost 90 per cent of all births. Söderbaum believed that this discrepancy proved that women would abandon traditional help-women if the state increased the supply of trained midwives. $^{60}$

There is no doubt that a similar social background to their clientele provided midwives with a considerable advantage over physicians in their efforts to influence the behaviour of parish residents. Doctors who worked in the Sundsvall region usually came from the south of the country and had little in common with the local culture or social environment of their patients. Of the four district physicians employed in the Sundsvall region between 1860 and 1890, two had fathers who were priests, and another was the son of a foundry owner. Only Dr Tornmark, who took up his position in 1881, had a less alien background: he had grown up on a farm. Without exception, all four of these men came from southern Sweden but the midwives often were born in a nearby, if not the same, parish in which they would later be employed. ${ }^{61}$

Midwives' close attachment to the Sundsvall region was particularly true until the 1880 s but thereafter many who found employment there came from much farther away. It is possible to determine the province of birth for all but two of the thirty-seven midwives employed in the rural parishes of the region between 1860 and 1890. From 1860 to 1879 such information is available for thirteen of the sixteen midwives employed. Five of the eight women from Västernorrland were born in the Sundsvall district itself. Another two came from the neighbouring province of Jämtland and the remaining three from other provinces. Although very few of these women took up employment as midwives in their parishes of birth, four of them had lived more than twenty years in the parish where they later assumed their duties. Even Augusta Petersson, who had been born in Stockholm, had lived eleven years in Sättna before she started work as parish midwife. ${ }^{62}$

Beginning in the 1880s the number of women from other parts of the country who became midwives in the Sundsvall region rose considerably. Of the twenty-one women that first appear in the records in 1880, 1885 or 1890, only seven were from Västernorrland and only four from parishes in the Sundsvall region. The neighbouring parishes supplied an additional three midwives, but the others came from as far away as Östergotland and Malmöhus in the far south of the country. Unlike their predecessors, many of these women began their careers as midwives almost immediately after moving into the parish. ${ }^{63}$

It is impossible to determine the effect of midwives' short residence in the parish on their ability to gain the respect and confidence of local women. It may be that there was some

\footnotetext{
${ }^{60}$ RA, Medicinalstyrelsen, Series E5A, ‘Årsberättelser från provinsialläkare', vol. 25, report from Sundsvall district for 1885 .

${ }^{61}$ The four doctors were J J Westerberg, W Baggstedt, O Söderbaum, and S Tornmark. Biographical information about them is garnered from the following sources: J F Sacklén, Sveriges läkarehistoria, Stockholm, n.p., 1853, p. 398;
}

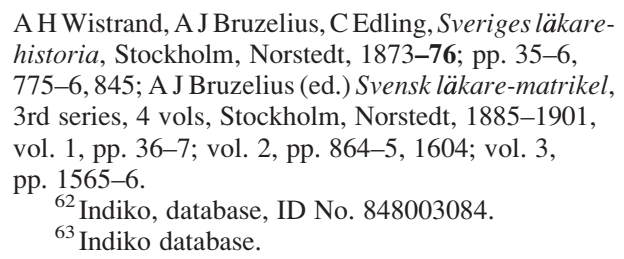




\section{Stephan Curtis}

suspicion of these outsiders, but it is also likely that their socio-economic background eased whatever barriers their recent arrival may have caused. Twenty-one of the husbands of the twenty-five midwives for whom we have such information were unskilled labourers, farmers or carpenters, three were skilled craftsmen, and one was a teacher. ${ }^{64}$

Returning to the case of Johanna Petersson in Attmar, there were several possible logistical and cultural reasons why she may not have been called to more births than she attended. On the one hand, Attmar was the second largest parish in the Sundsvall region, with an area of 400 square kilometres. From her home in the village of Karläng in the north of the parish it would have been difficult to reach some of the more distant houses if her presence had been requested. However, it is also possible that her recent arrival in the parish may have discouraged some women from calling upon her services. Petersson was born in Kronoberg, one of Sweden's southernmost provinces, and arrived in Attmar in 1885. All her counterparts from other parishes (Table 2) had either been born in the Sundsvall region or in one of the neighbouring provinces. The one exception was the midwife for Indal, who had arrived from the province of Malmöhus but had lived in the parish since $1878 .{ }^{65}$ We have no way of knowing whether women in Attmar considered Petersson as an outsider, or whether their perception of her influenced their decisions when they went into labour. We cannot be certain that local inhabitants felt some degree of suspicion or animosity toward Petersson but it would be equally unwise to dismiss the possibility entirely.

The annual report that the district physician in Härnösand submitted to the authorities in Stockholm in 1867 offers a window into the strong relationship that could exist between a midwife and women she attended. The doctor was quite critical of the midwife in Ljustorp parish for reasons unknown to us, but resigned himself to the fact that there was little he could do about her. There was, he said, no point in prosecuting her because whatever witnesses he could find to her alleged misbehaviour would side with her if the matter came to court. ${ }^{66}$ Apparently he was correct; Brita Kristina Sundqvist remained the parish midwife until 1891.

Midwives' close relationship with the women they visited enabled them to overcome some of the opposition to academic medicine. This is not to say that the reduction of maternal mortality, particularly during the later decades of the nineteenth century, was due entirely to midwives' ability to win the support of women. One could easily conclude that if the bonds between these practitioners and local women were as strong as the doctor in Härnösand envisioned, it is likely that bonds would have been stronger still between parturients and the traditional healers and help-women scattered throughout the region. Andersson's assertion that "Swedish midwifery was firmly established in the rural areas" in the nineteenth century suggests a level of state compulsion and public acquiescence that simply did not exist. Evidence from the Sundsvall region supports his assertion that the state deliberately tried to recruit midwives from farming families, but we cannot assume that this inevitably led to their acceptance by the population at large. ${ }^{67}$

\footnotetext{
${ }^{64}$ Indiko database.

${ }^{65}$ Indiko database, ID No. 846002666.

${ }^{66}$ RA, Sundhets Collegium, Series E5A, ‘Årsberättelser från provinsialläkare', vol. 37,
}

annual report for 1867 from Härnösand district physician.

${ }^{67}$ Andersson, op. cit., note 25 above, p. 34. 


\section{Midwives and their Role in the Reduction of Direct Obstetric Deaths}

New legislation and blatant coercion certainly played a role and undoubtedly contributed to the gradual advance of academic medicine. Parish officials were eager to prevent, or at least discourage, women from consulting kloka gummor and other traditional healers. Measures enacted by local councils generally echoed those of the state, but parish leaders often dragged their heels. For example, some parishes ignored legislation passed in 1819 requiring each to hire a licensed midwife and making it illegal for a woman to carry out the duties of a midwife without possessing a licence. As late as the early twentieth century some parishes still refused to replace untrained by trained midwives. ${ }^{68}$

One of the measures that local authorities undertook was to eliminate the financial advantage that the use of these traditional practitioners offered potential mothers. On 12 December 1880, the parish council in Indal made it less economically attractive for women to employ unlicensed practitioners. It had come to the council's attention that the parish midwife had not been called to at least thirteen births. The members decided that the women involved would each be required to pay two kronor to the parish council who would then forward it to the parish midwife, Maria Pettersson. ${ }^{69}$ Such penalties effectively eliminated any possible financial advantage parents may have achieved by calling upon the services of a help-woman rather than a trained midwife. Unfortunately, we do not know how much midwives or help-women charged to deliver a child. In many cases it appears that midwives received no additional fees from the mothers to supplement the salary they received from the parishes. By the mid-1870s, however, this situation had changed. The Sundsvall district physician reported that some midwives in his district, in addition to the salary and other payments paid them by the parish, also received up to 7 kronor from each woman they delivered, although the fee of 1-2 kronor was more common. ${ }^{70}$

In 1875, Dr Söderbaum used a much more heartless strategy to encourage the use of parish midwives. He issued an ultimatum to women who might be considering using an unlicensed help-woman to deliver their children. He acknowledged that the distances involved often made it impossible for women who suddenly went into labour to call a midwife, and if they required assistance with the delivery they often had little alternative but to turn to someone else. Söderbaum refused, however, to accept this pragmatism as a legitimate excuse, and one can almost hear him berating these women for their poor planning. Instead of compassion and understanding he instead offered a simple warning: if complications arose during birth he would only come to assist if a midwife summoned him. Otherwise, if a woman had chosen to have her child delivered by an unlicensed practitioner, he would provide assistance only in cases of extreme emergency. ${ }^{71}$ It is probably safe to assume that even under these dire circumstances he would not have hurried.

It is, of course, impossible to gauge the deterrent value of such measures as those taken by the Indal parish council or the threats issued by Söderbaum as they tried to coerce and cajole women into having their children delivered solely by licensed midwives. We know

\footnotetext{
${ }^{68}$ Romlid, op. cit., note 7 above pp. 197-204, 291; Loudon, op. cit., note 10 above, pp. 408, Högberg, op. cit., note 30 above.

${ }^{69}$ Sundsvall, Medelpadsarkivet, Series A1:2 Indals Kommun Kommunalstämma protokoll (12 Dec. 1880).
}

\footnotetext{
${ }^{70}$ RA, Sundhets Collegium, Series E5A, 'Årsberättelser från provinsialläkare', vol. 46, report from Sundsvall District 1876.

${ }^{71}$ RA, Sundhets Collegium, Series E5A, ‘Årsberättelser från provinsialläkare', vol. 45, report from Wifstavarf, 1875.
} 


\section{Stephan Curtis}

that by the 1880s there was growing support for academic medicine in the industrial parishes. As evidence for this we can look to the rapid growth of sickness insurance plans. In 1879 the district physician announced that workers and their families were abusing the provision of free medicine that these plans provided. This was forcing some sawmills to restrict such medication to the worker himself in an attempt to cut costs. $^{72}$ The degree to which demand for this new medicine extended into the more distant parishes is difficult to discern. Nonetheless, it appears that the likelihood of a midwife being called to attend a birth declined as the distance from the town increased.

Women who lived in the more agricultural parishes were less likely to use midwives than those who resided in the more industrial ones, and this pattern persisted from the early 1860 s until the end of the century. In 1870, for example, midwives attended less than 50 per cent of all births in the rural parishes compared with more than 70 per cent in those that were dependent upon industry. These figures rose quite steadily thereafter but the basic disparity remained. By 1890, 75 per cent of parents in the rural parishes but almost 90 per cent in those dominated by the sawmills were calling upon midwives to assist with the delivery of their children. ${ }^{73}$

We cannot attribute this spatial pattern solely to the greater supply of midwives in the parishes that relied most heavily upon the sawmill industry. Maps 3 and 4 identify the villages where midwives lived in 1865 and $1885 .{ }^{74}$ These maps also indicate the villages of residence for all but five women who died from direct obstetric causes, and the major roads and less-travelled paths that linked them to the nearest midwife. It is worth noting that the parishes of Attmar and Tuna shared the services of a single midwife in 1865. Furthermore, Engla Charlotte Fahlström, the midwife responsible for Selånger parish at that time, did not live in the parish but rather in the town itself.

Surprisingly there is no distinguishable spatial pattern between the places of obstetric deaths and the villages in which the parish midwives lived. This could be expected during the 1860 s, when the state of medical knowledge made it impossible for doctors and midwives to prevent puerperal infections. However, we might well expect to find some sort of pattern by the 1880 s by which time it was understood how these infections could be prevented and midwives were taught how to minimize the risks to new mothers.

In some parishes such as Hässjö and Ljustorp direct obstetric deaths occurred almost on the parish midwife's doorstep just as they had twenty years earlier (Map 4). In the village of Hassela in Attmar parish, approximately 15 kilometres from where the parish midwife lived, two women died from puerperal fever during the 1880s. By this time midwives could have prevented such deaths and so it is possible that these women had chosen not to call the midwife to deliver their children, or that the distance involved made it impossible for her to arrive in time.

Preliminary evidence suggests that women were more willing to have their children delivered by midwives if they were in the immediate vicinity but even by the 1880 s they

\footnotetext{
${ }^{72}$ RA, Medicinalstyrelsen, Series E5A, ‘Årsberättelser från provinsialläkare', vol. 4, report from Wifstavarf, 1879.

${ }^{73}$ S Edvinsson, A Brändström, J Rogers, 'Did midwives make a difference? A study of infant mortality in nineteenth-century Sweden'.
}

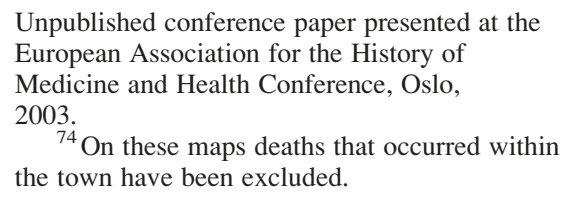




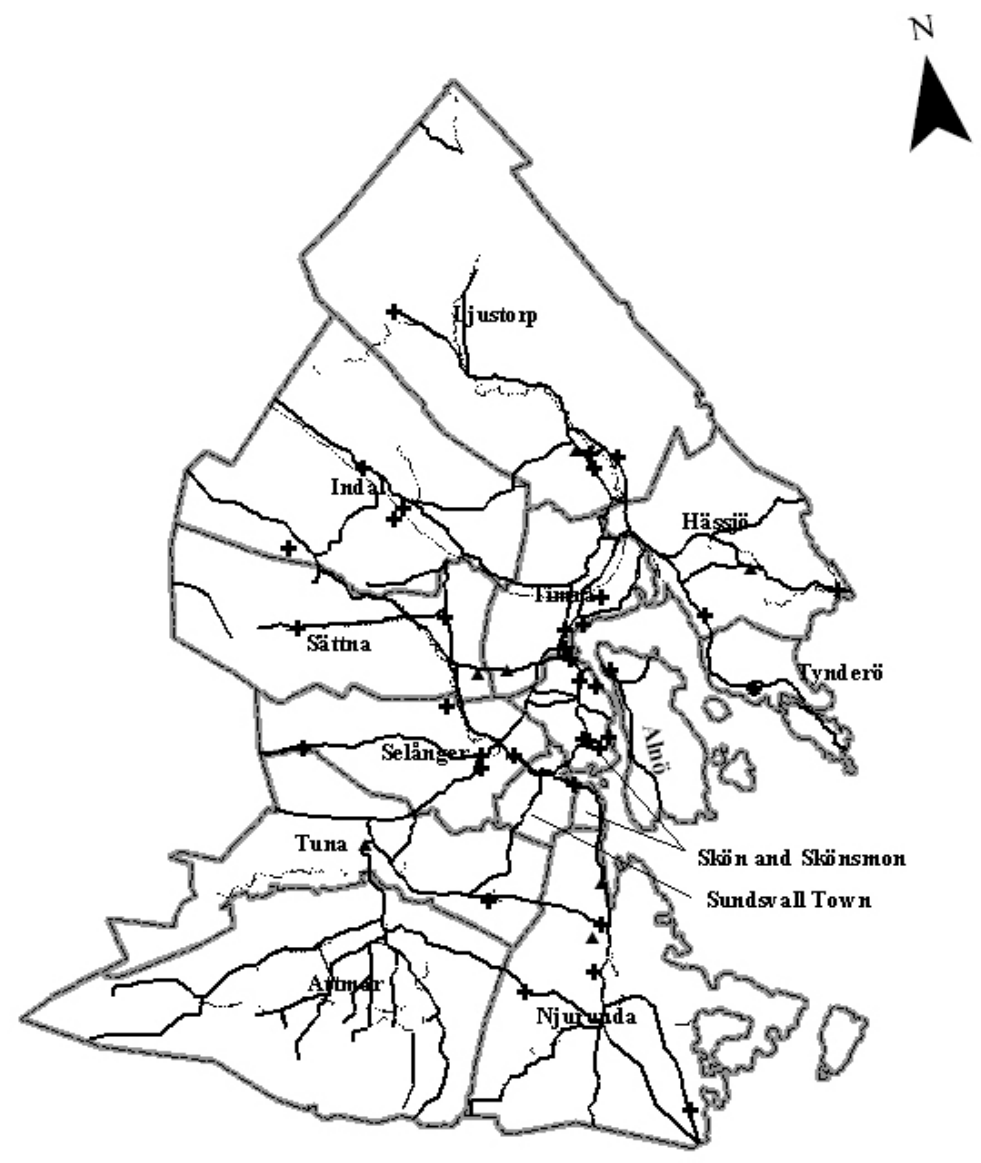

\section{Location of Midwives and Direct Obstetric Deaths}

+ Direct obstetric deaths (1860-69)

- Midwives' Residences (1865)

- Roads

-........- Rivers

parish boundaries

Map 3: The location of midwives (1865), direct obstetric deaths (1860-69), and transportation routes (1865) 

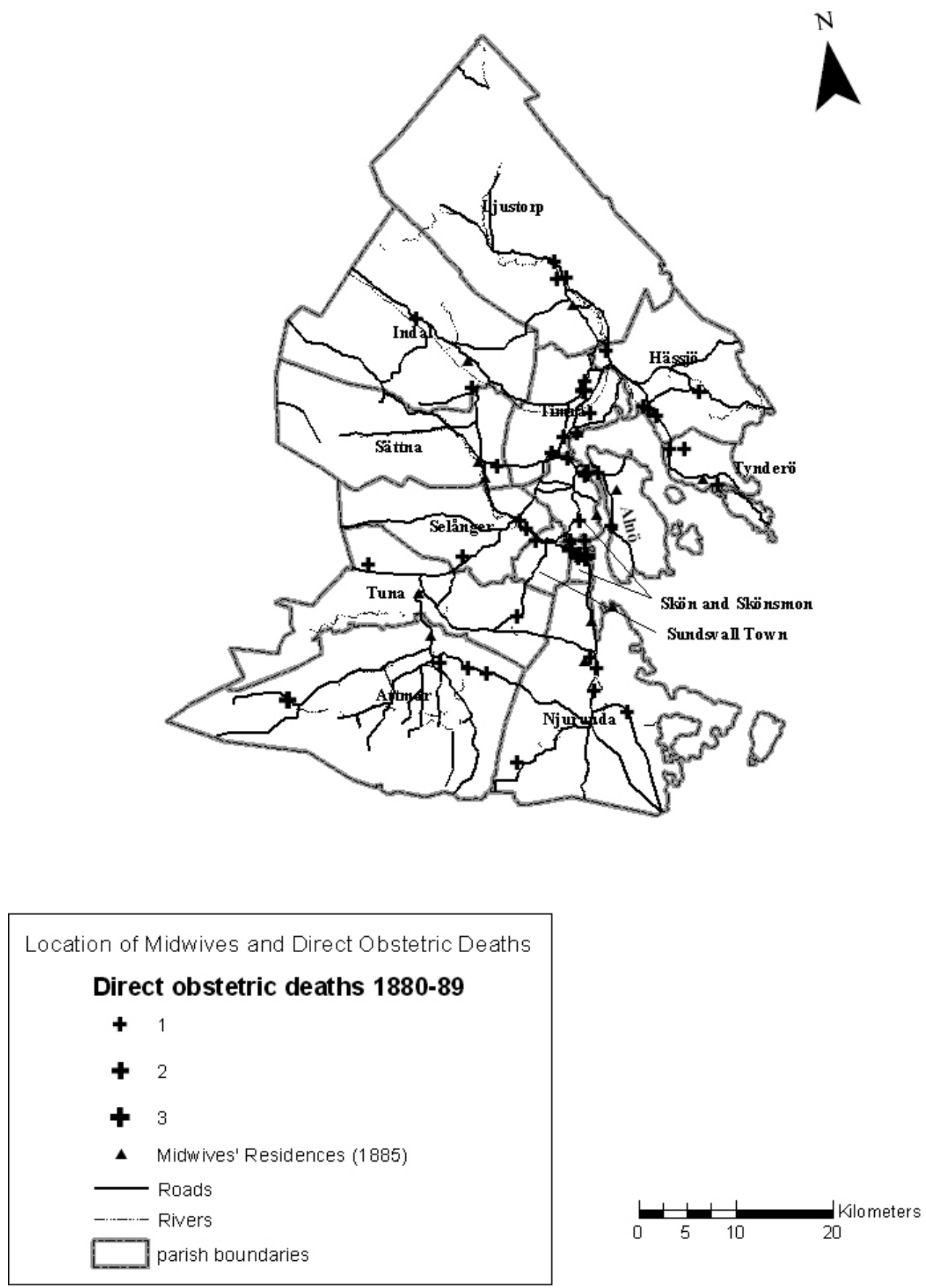

Map 4: The location of midwives (1885), direct obstetric deaths (1880-89), and transportation routes (1889) 


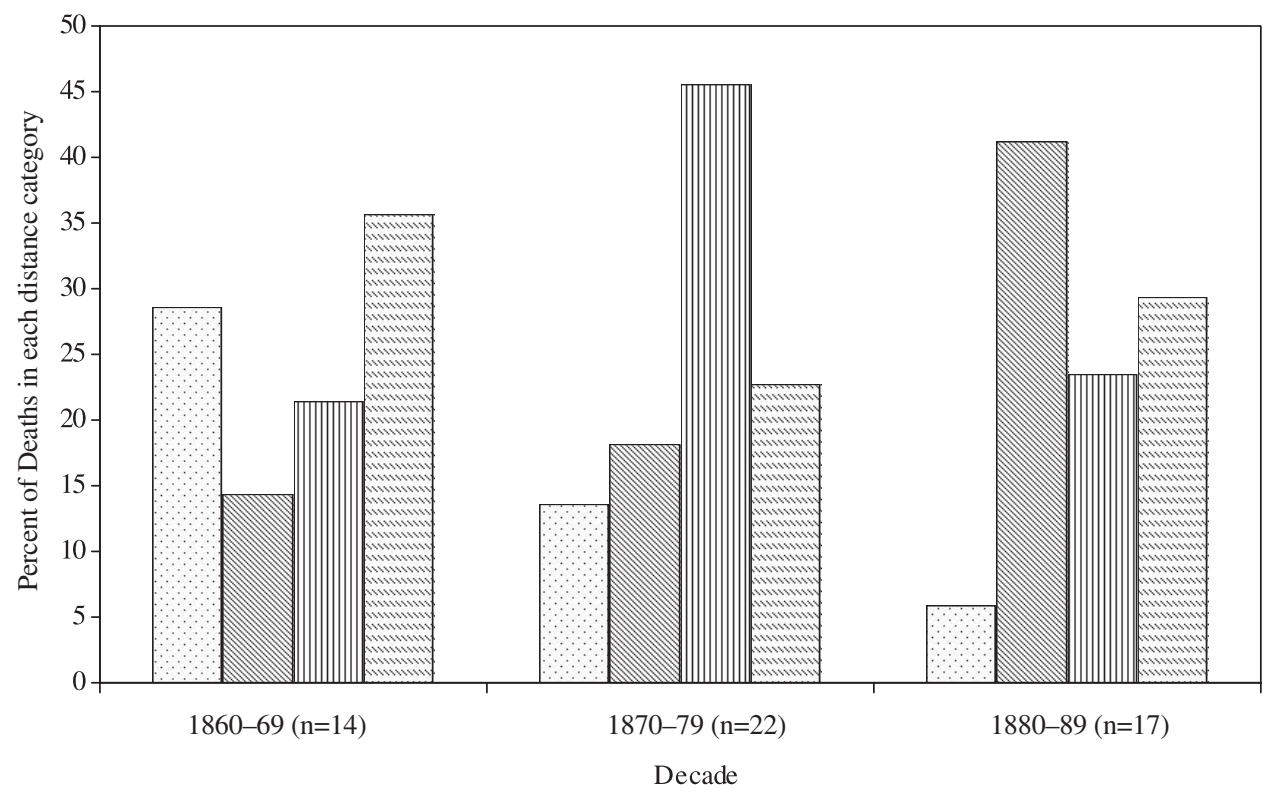

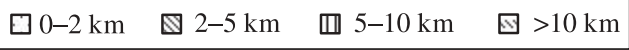

Figure 3: Distances between midwives and women who died from direct obstetric causes (inland parishes only).

Source: Demographic Data Base (Umeå, Sweden).

were not prepared to call on these practitioners if they lived even a relatively short distance away. Figure 3 illustrates the percentage of deaths from direct obstetrical causes that occurred in the inland parishes at four different distances from the nearest parish midwife for the decades 1860-69, 1870-79, and 1880-89. Examining similar patterns for the industrial parishes is less useful as many of these were quite small and this automatically reduces, if not eliminates entirely, the number of deaths that could occur more than ten kilometres from the midwife. At first glimpse the declining percentage of deaths occurring within two kilometres of the midwife suggests that the influence of midwives was increasing as the century progressed. This ignores the fact that during the 1880 s more than 40 per cent of all direct obstetric deaths still occurred within less than 5 kilometres from the nearest midwife. There are a number of potential explanations for the patterns that emerge, not least the small number of cases included, but one possibility is that women continued to have their children delivered by whichever practitioner was most readily available, regardless of training or the state's wishes.

There is no apparent spatial pattern to the direct obstetric deaths in the coastal parishes although, as we might expect because of their considerably smaller size, the geographical distance between the parish midwife and the women who died as a direct result of childbirth seems to have been even less of a factor than in the interior. These deaths seem to have occurred regardless of the proximity of the parish midwife. This is not what we would 


\section{Stephan Curtis}

expect to find. It was in the industrially based areas that midwives were most numerous and we can assume that it was there that academic medicine had achieved the most considerable advances. The development of a more complex road network through, and between, these parishes should also have facilitated midwives' ability to travel to women about to give birth. Figure 3 reveals that increased access to midwives was not in itself sufficient to reduce mortality from direct obstetric causes in the inland parishes.

Exploring the living standards among local inhabitants is the most profitable avenue of research because the relationship between poor social conditions and high maternal mortality is well recognized. Högberg and Boström note that for the nineteenth-century Swedish parishes they studied, "the socio-economic influence on reproductive health is the main explanation to the geographical differences of maternal mortality". ${ }^{75}$ Despite the rather advantageous supply of midwives in the coastal industrial parishes, the direct obstetric mortality rate among women aged between 15 and 45 was more than three times higher than in the more economically mixed inland parishes, although lower than for the two economically similar but coastal parishes of Hässjö and Njurunda between 1870 and 1879. As we have seen above, only in the 1880 s were the mortality rates in the various groups of parishes almost identical. This suggests that the unprecedented economic and demographic growth that peaked during the 1870s in coastal parishes of all types imposed considerable risks to the well-being of new mothers living there. ${ }^{76}$ Sören Edvinsson's examination of mortality patterns in the town of Sundsvall reveals that the highest mortality rates coincided with the economic boom of the 1860s and 1870s, and he attributes much of this to the overcrowded housing in which most people lived. ${ }^{77}$ Living conditions were similarly deplorable near the sawmills.

The importance of changing disease panoramas and their impact on maternal mortality has been a largely neglected field of inquiry but certainly one that offers much potential as a valuable explanatory tool. As stated above, Loudon argues convincingly that mortality among parturient women may well have risen during the 1870 s because of the increased virulence of the dominant strain of streptococcus. He writes:

Links between serotypes and specific disorders are highly complex.... But it is reasonable to postulate that the trends and fluctuations in deaths from puerperal fever, erysipelas, and scarlet fever were associated with fluctuations in the prevalence of certain serotypes which varied widely in their toxicity or virulence; and some of them may now have become extinct. ${ }^{78}$

Andersson and his co-authors also suggest that a change in the virulence of the dominant strain of streptococcus may have had an effect on maternal mortality from puerperal sepsis. The more than 140 deaths due to the scarlet fever outbreaks in these parishes in 1874-5 and

\footnotetext{
${ }^{75}$ Högberg and Broström, op. cit., note 20 above, p. 41. James McCarthy and Deborah Maine, although acknowledging the relationship between socio-economic status and maternal mortality, warn against ignoring other variables that can lead to birth-related complications. J McCarthy and D Maine, 'A framework for analyzing the determinants of maternal mortality', Stud. Fam. Plann., 1992, 23: 23-33, pp. 28-9.
}

\footnotetext{
${ }^{76}$ We must exclude the coastal agricultural parish of Tynderö and the inland economically mixed parishes of Tuna and Attmar from consideration as there are too few deaths to make any concrete conclusions. DDB files.

${ }^{77}$ These conditions were particularly dangerous for children under the age of fifteen but also for adults. Edvinsson, op. cit. note 14 above, pp. 181, 188-90, 215-19.

${ }^{78}$ Loudon, op. cit., note 10 above, p. 541; personal e-mail communication, 1 Oct., 2003.
} 


\section{Midwives and their Role in the Reduction of Direct Obstetric Deaths}

again in the early 1880 s seem to support this argument. ${ }^{79}$ Whether a few years later there was merely a happy coincidence of declining mortality from puerperal fever and a reduction in the virulence of the dominant strain of streptococcus remains unclear. If this was the case, the role midwives played in reducing the number of deaths due to puerperal fever after 1880 may need to be rethought, although their responsibility for at least some of that reduction cannot be disputed.

Evidence from contemporary societies indicates that the social status of women influences maternal mortality rates and the raising of women's social status was one of the founding goals of the Save Motherhood initiative launched in $1987 .{ }^{80}$ Women in a position to control their fertility, for example, are less likely to have large families and are obviously less at risk of dying as a result of childbirth. Despite the logic of this argument, research has shown that parity did not significantly increase the risk of dying from obstetrical complications in the Sundsvall region during the nineteenth century. ${ }^{81}$ Social expectations that the male should be the primary provider for his family perpetuated women's subordinate position in society. One of the consequences of this model was that the nutritional needs of their husbands took precedence over their own. Among other dangers, a reduction in nutritional intake increases the likelihood of obstructed labour and this was by far the major cause of direct obstetric deaths in Sweden during the nineteenth century. ${ }^{82}$

Women often found work at or near the sawmills during the 1870s but their participation in the paid labour force could not guarantee access to nutritious food for at least two reasons. First, their wages were lower than those of their male counterparts. Therefore, even if employed, single women could not be assured of sufficient nutritious food. Second, wives almost certainly subordinated their nutritional needs to those of their husbands. While it would be foolish to claim that women received no financial benefit from the expanding industrial economy, it would be equally naïve to assume that greater access to paid labour inevitably resulted in a satisfactory diet. Jane Humphries, although largely focusing on agricultural communities in Britain during the 1840s, argues that the rise of the male breadwinner model was particularly dangerous for women and especially for those who were pregnant or nursing. ${ }^{83}$ A recent study of six German regions during the eighteenth and nineteenth centuries similarly finds evidence that married women were more likely than their husbands to die from diseases that are somewhat influenced by nutritional levels. Women's nutritional well-being also seems to have been at least partially dependent upon the number of children in the family. When the supply of food was tight, it was usually the mother, not the father, who made do with smaller portions. ${ }^{84}$

${ }^{79}$ DDB files. Andersson, Bergström and Högberg, op. cit., note 16 above, p. 684. For a discussion of these scarlet fever epidemics, see S Curtis, 'Nutrition and patterns of scarlet fever morbidity and mortality during the epidemics of 1860-1890: the Sundsvall region', Soc. Hist. Med., 2004, 17: 199-221.

${ }^{80}$ E Hertz, J Hebert, and J Landon, 'Social and environmental factors and life expectancy, infant mortality, and maternal mortality rates: results of a cross-national comparison,' Soc. Sci. Med., 1994, 39: 105-14, p. 110; Yemane Berhane, Women's health and reproductive outcome in rural Ethiopia, Umeå University, 2000, p. 2.

\footnotetext{
${ }^{81}$ Andersson, Begrström, and Högberg, op. cit., note 16 above, p. 682.

${ }^{82}$ Högberg and Broström, op. cit., note 20 above,

${ }^{83}$ Jane Humphries, "'Bread and a pennyworth of treacle": excess female mortality in England in the 1840s', Cambridge J. Econ., 1991, 15:

${ }^{84}$ Stephan Klasen, 'Marriage, bargaining, and intrahousehold resource allocation: excess female mortality among adults during early German development, 1740-1860', J. Econ. Hist., 1998, 58: 432-67, pp. 445-6, 455.
} p. 39. 451-73. 


\section{Stephan Curtis}

Table 3

Tuberculosis mortality rate per 10,000 women aged 15-45

\begin{tabular}{|c|c|c|c|c|c|c|}
\hline \multirow[b]{2}{*}{ Parish group } & \multicolumn{2}{|c|}{$1860-69$} & \multicolumn{2}{|l|}{$1870-79$} & \multicolumn{2}{|c|}{$1880-89$} \\
\hline & $\begin{array}{c}\text { Mortality rate } \\
\text { per } 10,000\end{array}$ & No. & $\begin{array}{c}\text { Mortality rate } \\
\text { per } 10,000\end{array}$ & No. & $\begin{array}{c}\text { Mortality rate } \\
\text { per } 10,000\end{array}$ & No. \\
\hline Coastal industrial & 67.8 & 10 & 199.0 & 48 & 282.5 & 114 \\
\hline Coastal mixed & 69.4 & 7 & 52.3 & 7 & 119.0 & 20 \\
\hline Coastal agricultural & 0.0 & 0 & 153.3 & 4 & 68.7 & 2 \\
\hline Inland mixed & 9.9 & 1 & 7.9 & 1 & 173.2 & 23 \\
\hline Inland agricultural & 58.6 & 10 & 70.1 & 12 & 118.6 & 23 \\
\hline Town of Sundsvall & 169.8 & 25 & 356.6 & 72 & 267.6 & 73 \\
\hline Total & 76.9 & 53 & 159.8 & 144 & 212.5 & 255 \\
\hline
\end{tabular}

Source: Files from the Demographic Data Base (Umeå, Sweden).

Patterns of tuberculosis mortality can be used as a way to gauge living conditions and nutritional levels. ${ }^{85}$ Table 3 shows the mortality rate from tuberculosis among women aged 15 to 45 for each of the parish groups in the three decennial periods studied here. Beginning in the 1870 s, and certainly by the 1880 s, the disease had became largely endemic throughout the region but especially in the coastal-industrial parishes. ${ }^{86}$ Tuberculosis mortality rates in those parishes even surpassed the rates found in the town itself. The most likely explanation is that the cramped and unsanitary living quarters in which most sawmill workers and their families lived greatly increased the likelihood of contracting the disease. Poor nutrition also increased susceptibility to, and/or the likelihood of dying from it. The small number of deaths from the disease in many of the parish groups makes it impossible to make any firm comparisons between them. However, there is no doubt that the conditions in the parishes dominated by sawmills must have been particularly unhealthy for women, but other factors must have been at work.

Discussion of how deaths during the 1870s due to direct obstetric causes in the industrial parishes may have been partially caused by over-crowding and a lack of nutrition does not bring us closer to understanding why these mortality rates were even higher in the group of inland agricultural parishes during that decade. The low tuberculosis mortality rate shown in Table 3 suggests that inhabitants there did not experience the cramped and unsanitary living conditions that characterized parishes such as Skön and Alnö. It is also safe to assume that they enjoyed a more varied diet and higher levels of nutrition than those living near the sawmills.

By the 1880s the mortality rate from direct obstetric causes was almost identical across all groups of parishes suggesting that whatever obstacles had existed to the advance of academic medicine had largely been overcome. The explanation for this process remains

\footnotetext{
${ }^{85}$ For the relationship between nutrition and tuberculosis, see B-I Puranen, Tuberkulos: en sjukdoms förekomst och dess orsaker, Sverige 1750-1980, Umeå University, 1984, p. 352; P Lunn,

'Nutrition, immunity and infection', in R Schofield,
}

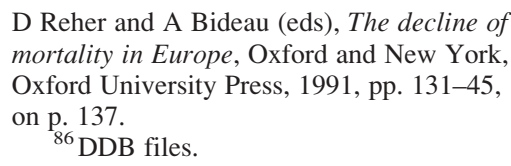




\section{Midwives and their Role in the Reduction of Direct Obstetric Deaths}

elusive but it is possible that local newspapers played no small role. Advertisements, and reports of the latest medical treatments, revealed a gradual movement away from traditional remedies towards the medicine practised by trained practitioners. Announcements for folk cures continued to sprinkle the pages of local newspapers but they did so with declining frequency as the century progressed. Another difference between the contents of newspapers in the late 1860s and mid-1880s was in the way medical treatments were advertised. Manufacturers gradually abandoned their reliance on vague and anonymous assurances that their products had proved effective, and increasingly called upon the authority of renowned physicians to endorse their cures and remedies. ${ }^{87}$

Newspapers also played a more informative role about matters of public health than they had done previously. When the state introduced its new Public Health Act in 1874, the Sundsvalls-Posten carried a lengthy account of it. ${ }^{88}$ Newspapers also began publishing summaries of the town doctor's annual reports. These included morbidity and mortality statistics for the major endemic and epidemic diseases that had visited the town during the previous year, and discussions of the various factors that could affect levels of health such as the quality of water and housing. ${ }^{89}$ In 1890 one of the most powerful examples of how far medicine and popular interest in medical matters had come during the course of the nineteenth century occurred. In two successive issues in mid-November the newspaper devoted no less than half a page to Koch's study of tuberculosis. ${ }^{90}$

\section{Conclusion}

This study began by questioning the assumption that greater access to midwives was instrumental to the reduction in direct obstetric mortality evident in the Sundsvall region. There is no doubt that the mortality rate from this cause was significantly lower in 1890 than it had been even at mid-century, and there are numerous plausible explanations why this occurred. We must not discount the roles played by diligent local medical practitioners and the legislation passed by equally committed politicians. The state pursued a comprehensive plan to increase the number of highly skilled midwives throughout the country. Local physicians, at least in the Sundsvall region, often praised these women for their exemplary work. Beginning in the early 1880 s, midwives learned how to prevent puerperal sepsis and maternal mortality began to fall even more rapidly than it had previously. By the 1890 s midwives were attending almost 80 per cent of births compared to only 40 per cent in the 1860s. In many ways then, this is indeed a story of success in which determined politicians and trained practitioners combined their efforts to make childbirth safer.

There is another side to this story requiring an entirely different perspective that poses different questions. Instead of trying to explain why 80 per cent of parturients in Sweden were delivered by midwives, this study tries to understand why almost 20 per cent were not. This approach makes the not unreasonable claim that women made their own decisions about who would or would not deliver their children. They did not necessarily follow the wishes of doctors and midwives, although there is evidence that towards the end of the

${ }^{87}$ Sundsvalls-Posten, No. 36, 27 Mar. 1880.

${ }^{88}$ Sundsvalls-Posten, No. 126, 27 Oct. 1874.

${ }^{89}$ Sundsvalls-Posten, No. 30, 24 Feb. 1890.

\footnotetext{
${ }^{90}$ Sundsvalls-Posten, No. 179, 17 Nov. 1890; No. 180, 19 Nov. 1890
} 


\section{Stephan Curtis}

century more and more did so. Instead, for most of the period studied here, parturients made their decisions based on a number of practical criteria that included proximity to the nearest midwife. However, there is ample reason to suspect that even into the 1880s many women did not call upon the services of a trained midwife even if she lived only a few kilometres away.

There is no way of definitively knowing why women made the choices they did, but this does not mean that we should not try to understand the culture in which they lived. The later nineteenth century was a period of tremendous medical conflict. On the one hand, the state became more involved in the realm of public health and the medical profession was able to claim limited success against some diseases. On the other hand, the presence of quacks and help-women proved that the reach of government officials, doctors, and midwives extended only so far. Some women in the Sundsvall region, particularly those living farthest from the town, seem to have been the most reluctant to abandon old ways for the new. Perhaps their suspicions of new methods were heightened if the parish midwife was new to the parish. This may explain why the recently arrived midwife in Attmar parish attended only about half of all births during the mid-1880s. In contrast, her more established counterparts in other parishes were called to almost 80 per cent of all births.

There can be little doubt that the rapid economic transformation that the Sundsvall region underwent from the late 1860 s until the early 1880 s greatly compromised the health of people living in parishes dominated by the sawmills and in the town. Mortality figures suggest that women were particularly vulnerable. Tuberculosis mortality rates for women aged between 15 and 45 during the 1870s were much higher in the coastal industrial parishes than anywhere else in the region. By the 1880s these figures even surpassed those for the town itself. Deplorable living conditions certainly contributed to tuberculosis mortality. However, we should not dismiss the role played by social mores that required a woman to sacrifice her own needs so that her children and husband might have sufficient food.

Living conditions may have improved somewhat in the late 1880s and certainly midwives' ability to prevent puerperal sepsis contributed to the reduction of maternal mortality. But focusing on these matters leads us into the trap of ignoring the women themselves. Surely it was ultimately up to them who attended the birth of their children. One of the reasons maternal mortality declined so markedly in the Sundsvall region during the last decades of the nineteenth century was because women were more inclined to call a midwife. Perhaps female friends, neighbours and family members made them aware that childbirth was much safer if a midwife was present. This was also a time when news about a broad array of medical issues could be found in the newspapers and that probably also played some role in women's decisions.

In some ways at least this study illustrates the danger of ignoring the influence of traditional cultures if the goal of reducing maternal mortality is to be achieved in the developing countries of today. Government officials may have the will, financial resources may be found to reduce poverty and improve living standards, and trained medical practitioners armed with the most modern skills can be mobilized to ensure safer births. This is all immaterial if women choose not to call upon the services that midwives, doctors, and hospitals can provide. 